\title{
Programme recommendations for the prevention of mother-to- child transmission of HIV: A practical guide for managers
}

\author{
Naomi Rutenberg \\ Population Council \\ Sam Kalibala \\ Population Council \\ Carolyn Baek \\ James Rosen
}

Follow this and additional works at: https://knowledgecommons.popcouncil.org/departments_sbsr-hiv How does access to this work benefit you? Let us know!

\section{Recommended Citation}

Rutenberg, Naomi, Sam Kalibala, Carolyn Baek, and James Rosen. 2003. "Programme recommendations for the prevention of mother-to-child transmission of HIV: A practical guide for managers," HIV/AIDS Working Paper. New York: UNICEF. 


\section{PROGRAMME RECOMMENDATIONS FOR THE PREVENTION OF MOTHER- TO-CHILD TRANSMISSION OF HIV}

\section{A PRACTICAL GUIDE FOR MANAGERS}

NAOMI RUTENBERG

SAM KALIBALA CAROLYN BAEK

JAMES ROSEN 
Programme recommendations for the prevention of mother-to-child transmission of HIV: a practical guide for managers

(C) United Nations Children's Fund (UNICEF), New York, 2003

UNICEF

3 UN Plaza, NY, NY 10017

August, 2003

This is a working document. It has been prepared to facilitate the exchange of knowledge and to stimulate discussion.

The text has not been edited to official publication standards and UNICEF accepts no responsibility for errors.

The designations in this publication do not imply an opinion on legal status of any country or territory, or of its authorities, or the delimitation of frontiers.

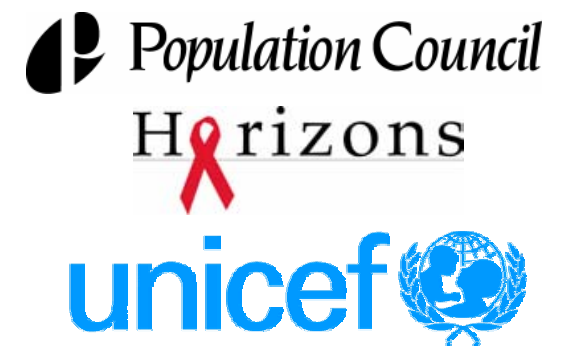




\begin{abstract}
This guide provides specific information for improving and scaling-up prevention of mother-to-child transmission of HIV [PMTCT] programs, based on what program managers and evaluators identify as successful strategies. The guide is intended for use by national-level PMTCT teams for starting or scaling up PMTCT programs. With appropriate adaptation, national officials can disseminate the guide to district level authorities, site managers, and health workers.

The recommendations in this guide draw on this body of knowledge, including primarily from an IATT-commissioned evaluation of the eleven pilot projects, carried out by the Population Council between March and December 2002 in close consultation with UNICEF and other Inter-Agency Task Team [IATT] members. Sources include progress reports from the country pilots, interviews, rapid assessments in Rwanda and Zambia and discussions at a collaborative analysis meeting held in December 2002.

The guide is divided into four chapters: 1) components introduced into the PMTCT program; 2) components strengthened by the PMTCT program; 3 ) systems; and 4) scale-up. The document is structured so that users can either read it from start to finish for help in developing a comprehensive PMTCT program or dip into it at specific points for guidance and resources on a particular component or system.
\end{abstract}

\title{
KEYWORDS:
}

HIVIAIDS, Mother-to-Child Transmission of HIV [MTCT], Care and Support, Voluntary Counseling and Testing [VCT], and Scale-up. 


\section{Acknowledgements}

We would like to acknowledge the contributions of the many people who gathered data, shared experiences, and reviewed drafts of this document. Specifically, we would like to thank Dr. Chipepo Kankasa and Dr. Haritiana Rakotomamonjy in Zambia; Dr. Andre Musemakweri, Dr. Paul Edwards, and Dr. Robert Lim Lim in Rwanda; Dr. Luis Roberto Escoto and Dr. Xioleth Rodriguez in Honduras; Dr. P.L. Joshi and Dr. Anne Vincent in India; the MTCT managers and UNICEF focal points in the pilot countries who responded to questionnaires and request for interviews; Dr. Doreen Mulenga and the PMTCT team at UNICEF Headquarters; the regional UNICEF focal points; and the Inter Agency Task Team on PMTCT. We are also grateful to Dr. Doreen Mulenga, Dr. Helene Moller, Dr. Mary Mahy and IATT members from UNFPA and WHO that provided helpful comments on an earlier draft. We would also like to acknowledge the assistance of Malea Hoepf from the Population Council.

Financial support for this evaluation was provided by the UNAIDS Secretariat on behalf of the IATT through a Memorandum of Understanding between UNICEF with the Population Council (MOU/PD/HLTH/01-005) and the Population Council's Horizons Program.

The Population Council's Horizons Program is implemented by the Population Council in collaboration with the International Center for Research on Women, International HIV/AIDS Alliance, Program for Appropriate Technology in Health, Tulane University, Family Health International, and Johns Hopkins University. Horizons is funded by the U.S. Agency for International Development, under the terms of HRN-A-00-97-00012-00. The opinions expressed herein are those of the authors and do not necessarily reflect the views of the U.S. Agency for International Development.

The Population Council is an international, nonprofit, nongovernmental institution that seeks to improve the wellbeing and reproductive health of current and future generations around the world and to help achieve a humane, equitable, and sustainable balance between people and resources. The Council conducts biomedical, social science, and public health research and helps build research capacities in developing countries. Established in 1952, the Council is governed by an international board of trustees. Its New York headquarters supports a global network of regional and country offices.Horizons is funded by the Global Bureau of Health/HIV-AIDS, U.S. Agency for International Development, under the terms of Award No. HRN-A-00-97-00012-00.

The views expressed in this document by the named contributors are solely the responsibility of those contributors. 


\section{Acronyms and Abbreviations}

$\begin{array}{ll}\text { AIDS } & \text { Acquired Immunodeficiency Syndrome } \\ \text { ANC } & \text { Antenatal care } \\ \text { ARV } & \text { Antiretroviral } \\ \text { AVSI } & \text { Volunteers Association for International Service } \\ \text { AZT } & \text { Zidovudine } \\ \text { BFHI } & \text { Baby-Friendly Hospital Initiative } \\ \text { CBO } & \text { Community-based organization } \\ \text { CDC } & \text { Centers for Disease Control and Prevention, USA } \\ \text { DHS } & \text { Demographic and Health Surveys } \\ \text { ELISA } & \text { Enzyme Linked Immunosorbent Assay } \\ \text { HAART } & \text { Highly active antiretroviral therapy } \\ \text { HIV } & \text { Human Immunodeficiency Virus } \\ \text { IATT } & \text { Inter Agency Task Team on Prevention of HIV Transmission in } \\ \text { IEC } & \text { Pregnant Women, Mothers, and Their Children } \\ \text { IMCI } & \text { Information, education, and communication } \\ \text { M2M2B } & \text { Integrated Management of Childhood Illness } \\ \text { M and E } & \text { Mothers-to-Mothers-to-Be program, South Africa } \\ \text { MCH } & \text { Monitoring and Evaluation } \\ \text { MTCT } & \text { Maternal-child health } \\ \text { NGO } & \text { Mother-to-child transmission of HIV } \\ \text { NVP } & \text { Nongovernmental organization } \\ \text { PLHA } & \text { Nevirapine } \\ \text { PMTCT } & \text { People living with HIV/AIDS } \\ \text { STI } & \text { Prevention of mother-to-child transmission of HIV } \\ \text { TAC } & \text { Sexually transmitted infection } \\ \text { TB } & \text { Technical Advisory Committee, Botswana } \\ \text { TBA } & \text { Tuberculosis } \\ \text { UNAIDS } & \text { Traditional birth attendant } \\ \text { UNICEF } & \text { Uoint United Nations Programme on HIV/AIDS } \\ \text { USAID } & \text { United Nations Children's Fund } \\ \text { VCT } & \text { Voluntary counseling and testing for HIV } \\ \text { WHO } & \end{array}$




\section{Table of Contents}

Abstract 1

Acknowledgements $\quad 2$

Acronyms and Abbreviations 3

Executive Summary

Error! Bookmark not defined.

I. Components to Introduce into PMTCT Programs 9

I.A. Voluntary Counseling and Testing ....................................................... 10

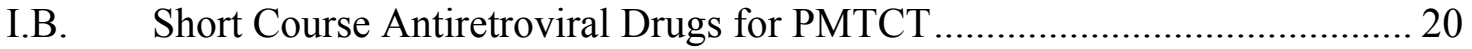

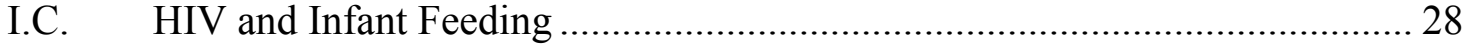

I.D. Male Involvement and Support................................................................... 37

II. Components to be Strengthened by PMTCT Programs 41

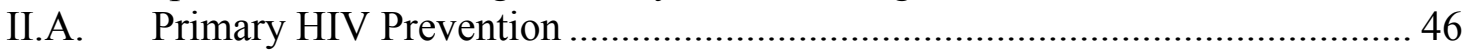

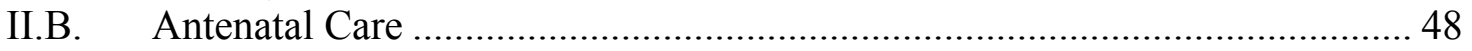

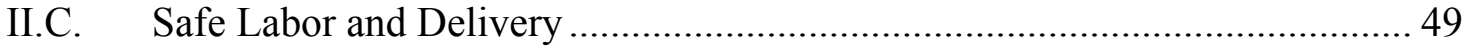

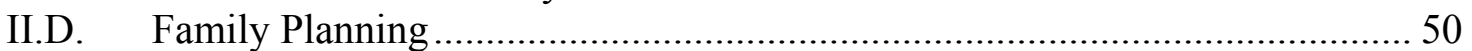

II.E. Care and Support for HIV-positive Women, Partners, and their Children ..... 51

III. Systems for PMTCT 54

III.A. Community Engagement and Advocacy Strategy and Implementation......... 54

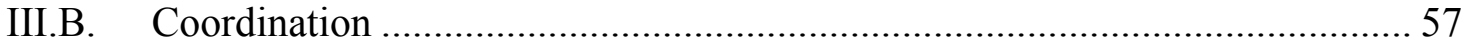

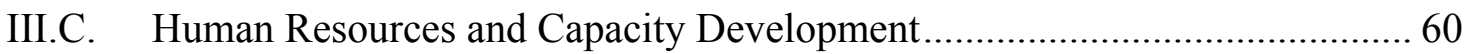

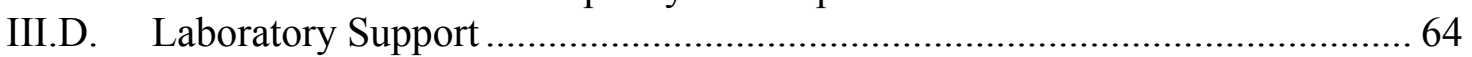

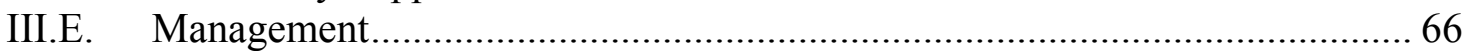

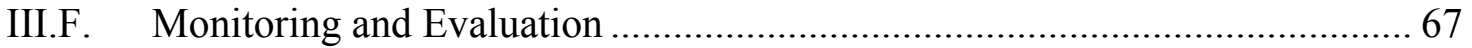

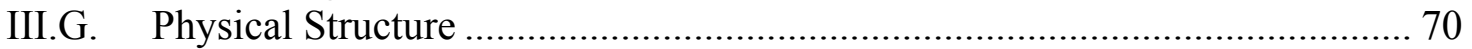

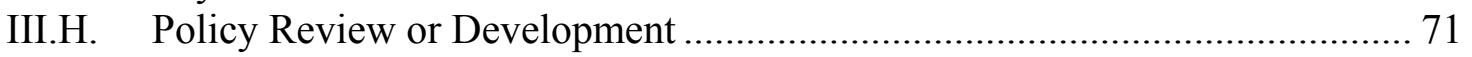

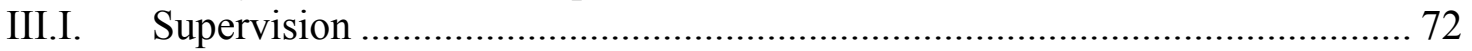

III.J. Supplies...................................................................................... 74

$\begin{array}{lll}\text { IV. Scaling Up } & 76\end{array}$

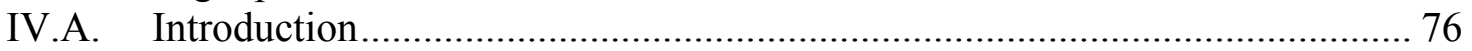

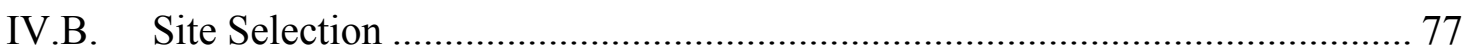

IV.C. Financing and Sustainability of Scaled-Up Programs ................................. 78

\section{Text Figures and Tables}

Figure 1 Structure of the Guide ........................................................................... 7

Table 1 Essential Components of VCT 11

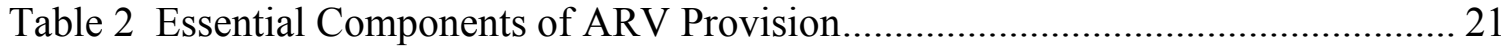

Table 3 Essential Components for HIV and Infant Feeding ..................................... 29

Table 4 Essential Components for Male Involvement.............................................. 38

Table 5 Recommended Actions for PMTCT Programs to Strengthen Key MCH and HIV

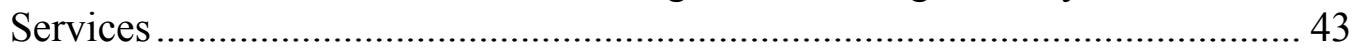

Table 6 Suggested Roles for Coordinating Teams...............................61

Appendices

Appendix A. Useful Documents 89

$\begin{array}{lr}\text { Appendix B. References } & 102\end{array}$ 


\section{Executive Summary}

\section{The Context for PMTCT}

The effects of the HIV pandemic among young children are serious and far-reaching. UNAIDS estimates that 800,000 children were infected in 2001, almost all through transmission of the virus from their mothers during pregnancy, childbirth, or breastfeeding. Of these, seven of each eight live in sub-Saharan Africa and most of the rest live in South and Southeast Asia. AIDS has reversed years of steady progress in child survival, and has already doubled infant death rates in the worst-affected countries. To begin steps to combat mother-to-child transmission of HIV (MTCT) ${ }^{1}$, in 1999 the UNAIDS Secretariat, UNFPA, UNICEF, and WHO launched the Inter Agency Task Team on Prevention of HIV Transmission in Pregnant Women, Mothers, and Their Children (IATT). The IATT aims to give strong, coordinated leadership and guidance to countries for prevention of MTCT (PMTCT). In the view of the IATT, PMTCT is part of broader strategies to prevent the transmission of HIV and sexually transmitted diseases, to care for HIV-positive women and their families, and to promote maternal-child health $(\mathrm{MCH})$.

The IATT has proposed the following four-pronged approach for the prevention of HIV transmission to pregnant women, mothers, and their children:

1. Primary prevention of HIV infection in women

2. Prevention of unintended pregnancy among HIV-infected women

3. Interventions to reduce transmission from HIV-infected pregnant and lactating women to their children

4. Care and support of women, children, and families infected and affected by HIV/AIDS

Effective interventions have dramatically reduced the number of children born with HIV in wealthy and middle-income countries. Yet significant financial and technical challenges remain to reduce these numbers in poor countries. To address these challenges, since 1999 UNICEF has supported eleven pilot projects in Africa, Asia, and Latin America. The pilot sites are in prestigious teaching hospitals, crowded urban health centers, poorly resourced district hospitals, and rural health posts. They are in areas of high as well as low HIV prevalence. The secretariats that manage the projects vary greatly in their composition, structure, and relationship with other HIV and maternalchild health programs. The pilots aim to test the feasibility and sustainability of carrying

\footnotetext{
${ }^{1}$ MTCT means transmission of HIV to a child from an HIV-infected woman during pregnancy, delivery or breastfeeding. The term is used in this document because the immediate source of the child's HIV infection is the mother. The more technical term is vertical transmission. Use of the term MTCT is not meant to imply blame whether or not a woman is aware of her own infection status. A woman can acquire HIV through unprotected sex with an infected partner, through receiving contaminated blood or through nonsterile instruments or medical procedures. However, HIV is usually introduced into the family through the woman's sexual partner.
} 
out PMTCT programs in settings typical of poor, resource-constrained countries, to measure program impact, and to provide guidance for expansion of successful programs and initiation of PMTCT programs in other countries.

While improving access to and the quality of PMTCT services is a central concern, countries must urgently scale up the availability and coverage of PMTCT services to meet the global goal set at the UN General Assembly Special Session on HIV/AIDS in 2001 and reiterated by the Special Session on Children in 2002. This goal is to reduce the proportion of infants born with HIV by 20 percent by 2005 and 50 percent by 2010 .

This document provides specific guidance for improving and scaling up PMTCT programs, based on what program managers and evaluators identify as successful strategies. Evaluation of PMTCT programs is still at an early stage. Very little strong evidence exists that ties a particular program strategy to actual reductions in HIV transmission or improvements in health outcomes. Nonetheless, countries have accumulated considerable experience about which PMTCT strategies are feasible and acceptable. The recommendations in this guide draw on this body of knowledge, including primarily from an IATT-commissioned evaluation of the eleven pilot projects, carried out by the Population Council between March and December 2002 in close consultation with UNICEF and other IATT members. The evaluation employed a mix of qualitative and quantitative methodologies, including:

- a review of progress reports from the country pilots, that included information on program inputs, activities, achievements, challenges, and (for some countries) costs;

- interviews (generally by telephone but also face-to-face at the International AIDS Conference 2002 in Barcelona) with key informants such as PMTCT program managers, and technical experts in charge of coordinating PMTCT activities at UNICEF and other donor agencies such as USAID;

- rapid assessments in two countries (Rwanda and Zambia) and site visits and faceto-face interviews with program managers in two other countries (Honduras and India) that gathered information from site managers, health workers, clients, and community members on PMTCT program inputs, the types of PMTCT services offered and received, the quality of those services, and health worker, client, and community reactions to the PMTCT program; and

- a collaborative analysis meeting held in September 2002 with members of the IATT. $^{2}$

The document also draws on the equally valuable experiences of PMTCT programs elsewhere and on the expertise of managers of national and international PMTCT technical support programs.

\footnotetext{
${ }^{2}$ For a report of the collaborative analysis meeting, see: Population Council and UNICEF. 2002. "PMTCT Evaluation Collaborative Analysis Meeting, Washington DC, September 9-10, 2002." Meeting Report. New York: UNICEF.
} 
The context, resources, and demand for PMTCT programs differ greatly across countries, as does the degree of program experience. Keeping in mind this variability, the guide includes the current consensus on good practices as well as alternatives which might be more appropriate in particular settings. Experts agree that the "state of the art" in PMTCT is changing quickly and that recommendations will certainly alter as the science advances and as more program experience is documented and disseminated.

\section{Using the Guide}

This guide is intended for use by national-level PMTCT teams for starting or scaling up PMTCT programs. With appropriate adaptation, national officials can disseminate the document to district level authorities, site managers, and health workers.

The document is divided into four chapters (see figure 1). The document is structured so that users can either read it from start to finish for help in developing a comprehensive PMTCT program or dip into it at specific points for guidance on a particular component or system. As such, some overlap exists. For example, discussion of systems needs is included both in chapter 1 (as it relates directly specific program components) and chapter 3 (which discusses overall systems needs).

\section{Figure 1. Structure of the Guide}

\begin{tabular}{|c|c|c|c|c|}
\hline \multirow[b]{2}{*}{$\begin{array}{l}\text { Strategic } \\
\text { Components }\end{array}$} & \multicolumn{4}{|c|}{ Program Prongs } \\
\hline & $\begin{array}{l}\text { Primary } \\
\text { prevention of } \\
\text { HIV infection } \\
\text { in women }\end{array}$ & $\begin{array}{l}\text { Prevention of } \\
\text { unintended } \\
\text { pregnancy } \\
\text { among HIV- } \\
\text { infected women. }\end{array}$ & $\begin{array}{l}\text { Interventions to } \\
\text { reduce transmission } \\
\text { from HIV-infected } \\
\text { pregnant and } \\
\text { lactating women to } \\
\text { their children }\end{array}$ & $\begin{array}{l}\text { Care and support } \\
\text { of women, } \\
\text { children, and } \\
\text { families infected } \\
\text { and affected by } \\
\text { HIV/AIDS }\end{array}$ \\
\hline $\begin{array}{l}\text { Chapter 1: } \\
\text { Components } \\
\text { introduced into the } \\
\text { PMTCT program }\end{array}$ & & & $\begin{array}{l}\text { HIV counseling and } \\
\text { testing } \\
\text { Short course } \\
\text { antiretrovirals } \\
\text { HIV and infant } \\
\text { feeding counseling and } \\
\text { support } \\
\text { Male involvement }\end{array}$ & \\
\hline $\begin{array}{l}\text { Chapter 2: } \\
\text { Components } \\
\text { strengthened by } \\
\text { the PMTCT } \\
\text { program } \\
\end{array}$ & $\begin{array}{l}\text { HIV } \\
\text { prevention }\end{array}$ & Family planning & $\begin{array}{l}\text { Antenatal care } \\
\text { Safe labor and } \\
\text { delivery }\end{array}$ & Care and support \\
\hline
\end{tabular}




\begin{tabular}{|l|c|}
\hline Chapter 3: & Communication \\
Systems & Coordination \\
& Human resources and capacity development \\
& Laboratory support \\
& Management \\
& Monitoring and evaluation \\
& Physical structure \\
& Policy review or development \\
& Supervision \\
& Supplies \\
Chapter 4: & Site selection \\
Scale Up & Financing and sustainability \\
\hline
\end{tabular}

Chapter 1 describes components introduced into the PMTCT program (sometimes referred to as the "core" components): HIV counseling and testing, short course antiretrovirals provision, HIV and infant feeding counseling and support, and promotion of male involvement and support. Because these activities form the heart of a PMTCT program, the guides devotes relatively more space to these components. The discussion of each component is meant to be self-contained and stand on its own. For each of these four major components, the document recommends best practices and other program options; uses illustrative country experiences; describes the systems needs; and lists key additional documents and resources.

Chapter 2 addresses components strengthened by the PMTCT program: primary HIV prevention, antenatal care (ANC), safe labor and delivery practices, family planning, and care and support for HIV-positive women, partners and children. For each of these services, the document discusses how PMTCT programs should employ three approaches - service integration and referral, linkages with other programs, and advocacy — to address PMTCT program goals.

Chapter 3 examines the cross-cutting systems needs of communication, coordination, human resources and capacity development, laboratory support, management, monitoring and evaluation, physical structure, policy review or development, supervision, and supplies. Each system requirement is addressed in question and answer format.

Chapter 4 takes up issues related to planning for scaling up and focuses on two key cross-cutting elements of scale up: site selection and financing and sustainability of scaled-up programs. The guide also addresses scaling up at various points throughout the first three chapters. 


\section{Components to Introduce into PMTCT Programs}

This chapter describes the four key components - often called the core componentswhich PMTCT programs introduce into antenatal care and maternal-child health services: HIV counseling and testing, short course antiretrovirals provision, HIV and infant feeding counseling and support, and promotion of male involvement and support. These service delivery elements directly address the third prong of MTCT programs, reducing transmission from HIV-infected pregnant and lactating women to their children:

- HIV counseling and testing are the entry point for PMTCT among HIV-infected and lactating women because they provide women with information and support to make subsequent decisions about antiretroviral therapy and infant feeding.

- The provision of short course antiretroviral therapy and helping women practice either exclusive replacement feeding or exclusive breastfeeding directly reduce the probability of MTCT by reducing the exposure of infants to the virus their mothers carry.

- Finally, the involvement of male partners of pregnant and lactating women in PMTCT programs support women's uptake of services and information.

For each of these components, the guide reviews key lessons learned from the initial PMTCT program experience. Then a table briefly lists guidance on recommended program actions and options which managers may prefer depending on the availability of resources, levels of HIV prevalence, and other local conditions. A discussion of how to implement each program component follows. Subsequent subsections address the systems needs, cost considerations, and useful sources for additional guidance. 


\section{I.A. Voluntary Counseling and Testing}

\section{Key Lessons}

- Documented experience from a number of countries shows that ANC/MCH programs can successfully incorporate voluntary counseling and testing (VCT) services into clinic and community settings.

- Such experience shows that incorporating VCT does not reduce ANC attendance or otherwise harm the quality of care.

- Unlike in other HIV testing situations, a number of clinic staff need to know the test result so that clients receive appropriate PMTCT care. Despite this constraint, with proper training and procedures in place, $\mathrm{ANC} / \mathrm{MCH}$ staff are able to keep the HIV status of their clients confidential.

- The uptake of VCT in ANC settings is still too low. Just over half of the women who attended ANC in the pilot PMTCT sites since their inception receive HIV counseling and testing. The main reasons for this low uptake are poor community mobilization, insufficient counseling time, and lack of male involvement.

- As programs go to scale, they must continue to test strategies to boost the use and improve the effectiveness of VCT.

\section{Recommended Program Actions for VCT}

To increase the uptake and effectiveness of VCT for PMTCT, programs should start with a policy that includes VCT services as a basic component of any ANC setting, include promotional campaigns and VCT for men and for young people, maintain good quality VCT in the ANC clinic or any other setting, link with care and support services, and reach out to the community with follow-up counseling and psychosocial support. 
Table 1 Essential Components of VCT

\begin{tabular}{|c|c|c|}
\hline $\begin{array}{l}\text { Essential Service } \\
\text { Component }\end{array}$ & Recommended Actions & Other Options \\
\hline a. Community Mobilization & $\begin{array}{l}\text { Educate community } \\
\text { members about HIV, } \\
\text { MTCT, and how to prevent. } \\
\text { Introduce notion that HIV } \\
\text { testing is offered as a } \\
\text { routine part of antenatal } \\
\text { care. } \\
\text { Collaborate with general } \\
\text { population VCT programs. }\end{array}$ & \\
\hline b. Routine ANC Health Talk & $\begin{array}{l}\text { Educate women about HIV, } \\
\text { MTCT, and how to prevent. } \\
\text { Reinforce talk with video. } \\
\text { Inform women of their right } \\
\text { to opt out of testing. }\end{array}$ & \\
\hline c. Pre-Test Counseling & $\begin{array}{l}\text { Provide small group (five to } \\
\text { eight clients) pre-test } \\
\text { counseling followed by } \\
\text { routine HIV testing and } \\
\text { inform mothers of right to } \\
\text { opt out. }\end{array}$ & $\begin{array}{l}\text { Use lay counselors to provide } \\
\text { individual pre-test counseling. } \\
\text { Promote and offer couple } \\
\text { counseling. } \\
\text { Offer pre-test counseling and } \\
\text { blood draw outside ANC for } \\
\text { male partners of women seen } \\
\text { in ANC. }\end{array}$ \\
\hline d. HIV Testing & $\begin{array}{l}\text { Conduct rapid testing in } \\
\text { ANC/MCH setting and } \\
\text { offer same day results if the } \\
\text { client wants. }\end{array}$ & $\begin{array}{l}\text { Offer rapid testing in the } \\
\text { community with trained lay } \\
\text { counselors, as part of outreach } \\
\text { ANC for women who may not } \\
\text { have easy access to ANC in } \\
\text { health facilities. } \\
\text { Test routinely, but give } \\
\text { women the chance to opt out } \\
\text { of learning their HIV results or } \\
\text { to choose when to learn their } \\
\text { HIV results. }\end{array}$ \\
\hline
\end{tabular}




\begin{tabular}{|l|l|l|}
\hline $\begin{array}{l}\text { Essential Service } \\
\text { Component }\end{array}$ & Recommended Actions & Other Options \\
\hline e. Post-Test Counseling & $\begin{array}{l}\text { The preponderance of HIV } \\
\text { counseling and testing } \\
\text { resources and time should } \\
\text { be devoted to post-test } \\
\text { counseling. }\end{array}$ & $\begin{array}{l}\text { Routinely schedule second } \\
\text { post-test session. }\end{array}$ \\
\hline $\begin{array}{l}\text { Use lay or peer counselors } \\
\text { to provide in-depth PMTCT } \\
\text { information appropriate to } \\
\text { the woman's HIV status at } \\
\text { the second post-test session. }\end{array}$ & $\begin{array}{l}\text { Offer VCT during labor. } \\
\text { fabor or Postpartum VCT }\end{array}$ & $\begin{array}{l}\text { Provide postpartum VCT to } \\
\text { help women make decisions } \\
\text { about infant feeding. }\end{array}$ \\
\hline $\begin{array}{l}\text { Facilitate support groups. } \\
\text { counseling }\end{array}$ & $\begin{array}{l}\text { Use peer counselors and lay } \\
\text { counselors to provide } \\
\text { ongoing counseling at the } \\
\text { PMTCT site, at community } \\
\text { settings and/or at home. }\end{array}$ & \\
\hline
\end{tabular}

2.a. Community Mobilization: To increase the proportion of women who are tested for HIV on their first visit for antenatal care, PMTCT sites should carry out extensive community mobilization activities using a variety of communication methods to stimulate community dialogue and educate men and women about HIV, MTCT, and how to prevent it. National countries should call upon regional communications experts to help them in developing appropriate communication strategies. PMTCT programs should collaborate with VCT programs aimed at the general population to ensure that couple counseling takes place and that general-purpose VCT programs adequately address PMTCT. Working through general-purpose programs will help ensure early male involvement in PMTCT and overcome an important obstacle to testing that many women face, the need to consult their spouse. The more discussion about HIV and MTCT in the community and among couples, the easier it will be for women to accept HIV testing within the ANC setting. Community promotion of VCT will also help address primary prevention of HIV in women, one of the four key PMTCT prongs. VCT promotion initiatives - using both mass media and interpersonal communication-should be tailored to women, young people (especially young women), and men. 
Country Experience: In Keemba village in Zambia, community mobilization efforts initiated through meetings with male village elders proved influential in promoting VCT. For example, one community leader was worried about the risk of HIV infection for himself, his wives, and his sons, and asked the staff from the PMTCT program to give a talk to his extended family. He and a number of his wives subsequently were tested for HIV. Several other men in the community and their wives later followed his lead and got tested (Mutunda 2001).

The New Start VCT centers in Zimbabwe use promotional campaigns that include mass media and interpersonal communication to market their services (Gosh et al. 2002).

2.b. Routine ANC Health Talk: Once women come for antenatal care, clinic staff should use the routine health ANC talk as an opportunity to educate clients about HIV, MTCT, and how it can be prevented. Staff should inform women that, owing to the need to prevent MTCT, the clinic has added HIV to the routine battery of ANC tests. Staff should also inform clients of their right to opt out of HIV testing, and give women the chance to ask questions as usual. The health talk should be reinforced with a video presentation. Following the talk, women should attend pre-test counseling in smaller groups of about five. Upon request, clinics should make individual pre-test counseling available.

Country Experience: In Botswana, PMTCT officials seeking to increase the relatively low levels of service utilization developed a sixteen-minute video for use in clinics. The video provides standardized information about the benefits of PMTCT to pregnant women and partners in a group setting before individual counseling. The program tested the effect of the video on acceptance of VCT during a one-month pilot period in twelve clinics and found that 68 percent of women who viewed the video accepted the HIV test versus just 52 percent of women who did not view the video (Smith 2002).

Routine HIV testing for ANC clients has worked successfully in the United States and Europe as well as in private hospitals in Nairobi, Kenya. Other possible alternatives include routinely testing for HIV but giving women the chance to opt out of learning their HIV results or to choose when to learn their HIV results.

Country Experience: At some of the sites in Honduras with high VCT uptake, the policy is for staff to strongly recommend HIV testing while respecting the decision of the client not to test. In these sites, pre-test counseling sessions are largely devoted to giving health information (Source: Baek, Rodriguez, and Escoto, 2002).

2.c. Pre-Test Counseling: Although clinics with sufficient staff should offer individual pre-test counseling, most sites lack counselors and face severe time constraints.

Fortunately, group counseling, in groups of about five, is a good alternative to individual pre-test counseling. Group counseling facilitates the provision of standardized messages. It also allows women who are too shy to raise questions to learn from the questions of other women and to understand that their peers have similar concerns. Groups can also introduce opportunities for peer counseling, for example by mothers to mothers-to-be. However, clinics must also give clients the chance to ask questions privately following a 
group session. To bypass the problem posed by staff shortages, one viable alternative to phasing out individual pre-test counseling is to employ lay counselors.

Country Experiences: In Abidjan, Cote d'Ivoire, the PMTCT program includes: group counseling sessions, free HIV testing with same-day results, provision of free antiretroviral drugs (ARVs), counseling of and support to mothers on infant feeding options, and free formula (Noba et al. 2002).

In the PMTCT program in a rural area of South India, high volume in the outpatient department makes it is difficult to offer individual pre-test counseling. In this setting, group counseling followed by individual counseling helps reduce the burden on staff and allows women to attend multiple sessions, thus reinforcing key messages (Vijaykumari et al. 2002).

In Mombasa, Kenya, the PMTCT program offers group pre-test counseling, requests women to provide written informed consent, and then uses rapid tests (Quaghebeur 2002).

In Mulago hospital, Uganda, the PMTCT programs does pre-test group counseling followed by rapid tests and same-day individual post-test counseling (Kibenge 2002).

2.d. HIV Testing: PMTCT programs should adopt the rapid HIV testing approach now becoming the norm in general population VCT programs. In many such programs a counselor or a VCT laboratory technician carries out the test. Rapid testing in general VCT programs has been associated with high proportions of clients seeking results. In PMTCT settings, ANC/MCH staff should carry out rapid testing and give women their results the same day unless they opt not to wait. Some PMTCT programs that conduct rapid tests do not give results to women on time because the tests are conducted in the main laboratory and often results are delayed. Some program officials have expressed concern that, since ANC women do not anticipate being tested, they may not be emotionally prepared to receive a result showing that they are infected with HIV. Given the limited experience in the ANC setting, programs need to monitor carefully the emotional reactions of clients to the rapid-results approach.

Country Experience: In Zambia, women gave the following reasons for not getting results: results were not ready; the counselor was not available; the woman lived far from the clinic, had to leave early, and could not wait. A client in Rwanda commented that the time needed to get results - one week - was too long. The availability of rapid tests would avoid many of these obstacles (Source: Kankasa et al., 2002)

2.e. Post-Test Counseling: Programs should devote most VCT resources and time to posttest counseling. Post-test counseling aims to:

- provide the HIV test result;

- give women emotional support; 
- make sure clients understand the result;

- discuss the implications of sharing results with other health workers;

- introduce PMTCT services to HIV-positive women; and

- present the range of services to both HIV-positive and HIV-negative women, including referral for care and support services and on going counseling if needed.

Programs can use structured counseling cards to ensure that counselors cover these important elements the session. Programs should give ample time for post-test counseling and routinely schedule a follow-up counseling session. Where staff is short, clinics can use lay and peer counselors to help provide follow-up counseling. For HIV-infected clients, programs should use the second post-test session to counsel on ARV use and adherence and on infant feeding. For all women regardless of HIV status, the second post-test session is ideal for in-depth counseling on preventing infection (or reinfection) of HIV and other sexually transmitted diseases. The second post-test session is an important chance to personalize prevention messages received during the health talk and group pre-test counseling, taking into consideration the woman's newly learned HIV status.

Country Experience: Most mothers interviewed in Zambia were pleased with the counseling received and the attitude of the health workers, although some wanted more counseling time. Some said the post-test counseling they received did not give them ample opportunity to ask questions and others received no advice on how to tell their spouse about their HIV status. Many said they needed more information on how to reduce their risk of infection and others wanted to know what being HIV-positive meant for themselves and their babies. These findings suggest the need to invest more time in post-test counseling (Source: Kankasa et al., 2002).

2.f. Labor or Postpartum VCT: Some programs have used HIV rapid testing for mothers whose first contact with the PMTCT site is during labor. The experience with those women testing positive is that they consistently agree to receive the intrapartum ARV dose (Veloso 2002). Programs could test the feasibility of such an approach to minimize missed opportunities. Programs should also offer untested women postpartum VCT to help them make an informed choice about infant feeding options. ${ }^{3}$

Country Experience: The Chris Hani Baragwanath Hospital in Soweto, South Africa offers postpartum VCT before discharge to all mothers not tested before delivering their baby. Lay workers do pre-test counseling and the program provides rapid, on-site HIV testing. Following confidential post-test counseling, the program offers HIV-infected clients infant feeding counseling and post-exposure prophylaxis for their infants. Women testing positive gain entry into follow-up care and support programs. Regular clinic staff

\footnotetext{
${ }^{3}$ In high-prevalence countries, programs might offer nevirapine to all women who go into labor before knowing their HIV status and then offer rapid HIV testing immediately after labor. For those women who test positive, the program could give their newborns nevirapine and AZT. The following section on ARVs presents an example of such an approach.
} 
has accepted the participation of lay counselors in postnatal wards and program has achieved a reasonably high VCT acceptance rate of 63 percent (Chersich et al. 2002).

2.g. Follow-up Support and Counseling: PMTCT programs need to bolster their efforts in this important but neglected area. Good follow-up reinforces infant feeding and family planning and helps address prevention of unwanted pregnancy among HIV-infected women and care and support. Care and support organizations have used a number of strategies for follow-up counseling and support, including facilitation of support groups, and use of peer and lay counselors to provide ongoing counseling at the PMTCT site, at community settings, or in the home. PMTCT programs should establish links with existing care and support organizations and test promising strategies to benefit their clients.

Country Experience: In Zimbabwe, over 100 women's associations, which include about ten members per group, provide HIV-infected women and their families with health education, and help with child care, housework, palliative nursing, and money for medical and funeral expenses. Members of established associations report lower levels of depression, somatic symptoms, anxiety, insomnia, and social dysfunction than nonmembers. They also report better adjustment and coping (Mukwashi 2002).

Grants from the recently-launched MTCT Plus initiative will better enable PMTCT programs to provide comprehensive care to mothers and their children, including ARV treatment (Rosenfield 2002).

\section{Systems Needs for VCT}

3.a. Coordination: PMTCT services are expanding at the same time that VCT services for the general population are growing, underlining the need for coordination between the two programs. Coordination is particularly important in the bulk purchase, importation, and distribution of HIV test kits. For purposes of bulk purchase the PMTCT and VCT programs should also link with other HIV testing units such as the HIV surveillance unit and the blood transfusion services. Coordination is also key for training and supportive supervision of counselors. Furthermore, since the male partners of ANC clients are unlikely to seek VCT in the ANC setting, collaboration with general VCT programs may enhance male involvement. One way to establish this link is to give women referral notes for their spouses to seek VCT at a general VCT facility. Also, staff at the general VCT facility should give men information about PMTCT and encourage them to refer their pregnant spouse or partner for VCT at the ANC site. Furthermore, all HIV community mobilization programs need to integrate PMTCT messages into their activities.

3.b. Human Resources and Capacity Development: Introduction of PMTCT requires significant additional training for a range of ANC clinic staff, including for:

- counselors in HIV rapid testing;

- lay and peer counselors in HIV counseling skills and PMTCT; 
- current HIV health educators to enable them to integrate PMTCT into their community mobilization activities; and

- counselors in general population VCT sites to include PMTCT issues as they counsel potential fathers and couples.

Low motivation, staff shortages, and heavy workloads afflict PMTCT programs in many countries. The ultimate, sustainable solution to these problems-overall economic improvement - is beyond the influence of PMTCT programs. Nonetheless, nongovernmental organizations (NGOs) and development partners have used innovative approaches to motivate government health workers. One example is to pay health workers for extracurricular work like community outreach, research, or home visits during their free hours. Such an approach can raise the compensation of health workers while keeping their interest in pubic service, but typically relies on continuous donor support and thus not financially sustainable over the long term.

Staff in many PMTCT programs have taken on extra workload without extra pay. The best way to address this problem is to hire additional workers. In low-prevalence settings such as Honduras, clinic staff cope with the added workload that the relatively few HIVpositive clients creates. Because the same ANC health worker usually provides both HIV- and pregnancy-related care, programs have a great need to reorganize their services to accommodate the new PMTCT components. Some PMTCT sites have designated one or two ANC staff to work full time on HIV-related care, including VCT, ARV provision, and support for infant feeding formula while other sites have made HIV the responsibility of all ANC staff.

Country Experience: In Zambia and Rwanda, PMTCT staff cite personnel shortages and heavy workload as among the key constraints to providing adequate VCT. Workers mention higher pay and time off from other duties to do counseling as incentives to better provide VCT (Source: Kankasa et al., 2002 and Pham, Musemakweri, and Stewart, 2002). A study of PMTCT programs in Uganda found an association between greater numbers of counselors and higher VCT uptake (Onyango 2002) and Botswana (Stocking et al. 2002).

Use of lay counselors may also help alleviate staffing shortages. Programs can recruit lay and peer counselors with relatively little bureaucratic effort and have used such lay staff in many countries to provide care and support to people living with HIV/AIDS (PLHAs). At the same time, programs need to provide incentives, training, and supervision to lay counselors to motivate and retain them and to ensure high quality performance. Counselors should meet regularly to discuss problems and help prevent burn-out.

Country Experience: In Chitungwiza, Zimbabwe, the PMTCT program identified thirtyfive lay counselors from local community organizations. The program trained them in a two-week course that emphasized practical application of counseling skills, and required them to sign a pledge to maintain client confidentiality. The counselors worked sixteen hours per month for a small stipend. With appropriate supervision, lay staff maintained professional counseling standards (Moyo et al. 2002). 
The HIV/AIDS Lay Counsellor Programme is an innovative partnership between the Department of Health and LifeLine Western Cape, South Africa. The LifeLine program recruits unemployed people from high-prevalence, disadvantaged communities, trains them in counseling and others areas of HIV/AIDS information and support, then deploys them in public health facilities. LifeLine provides the counselors with uniforms, insurance, transport money and ongoing training and supervision while the Department of Health pays their salaries. LifeLine supplies counselors for the PMTCT program and to facilitate peer education. PMTCT clinics using these counselors report very high success rates (Lifeline/Childline Western Cape 2002).

The Mothers-to-Mothers-to-Be (M2M2B) program in South Africa is a mentorship program for HIV-infected pregnant women. The program recruits HIV-infected mothers who recently gave birth to educate, counsel, and support HIV-infected pregnant women who attend ANC clinics. At every antenatal visit, mentors engage pregnant women, share personal experiences, encourage adherence to ARV treatment plans, and help them during their hospital stay. Mentors also receive continued education and support, including a small stipend. The first M2M2B program was started at a tertiary care hospital. M2M2B programs are scheduled to open at several primary care maternity centers in South Africa. Peer support mentorship programs fit seamlessly into routine antenatal care. Pregnant women enrolling in M2M2B have a better understanding and greater acceptance of interventions to reduce mother-to-child transmission. They are better able to participate in decision-making about mode of delivery, use of antiretroviral drugs, and feeding methods. The program helps educates pregnant women and mothers and thus empowers them in their respective families and communities. Empowerment contributes to destigmatization of HIV infection and improved community health (Besser 2002).

A further human resource issue specific to VCT is the need for supportive supervision to help counselors develop their skills and to minimize burn-out. PMTCT programs should develop links with existing HIV counseling organizations and obtain an experienced counselor to visit the PMTCT site regularly to provide support to the VCT counselors. Where such a facility is not within easy reach, counselors together with other members of the team should meet regularly to share experiences and support each other. Resources permitting, the program could hold staff retreats with an external counselor every three to four months.

3.c. Laboratory Support: VCT requires support from laboratory professionals for a variety of reasons. Countries which have not yet developed rapid test algorithms will need to assess combinations of rapid tests against existing gold standards to develop nationally accepted algorithms. Furthermore, programs will need to train counselors to perform rapid tests. When rapid test give discrepant results, programs should use laboratories re-test the specimens and confirm the results. Programs should routinely send a proportion of specimens tested by the counselors to the laboratory for quality assurance. 
3.d. Management: The proposed VCT strategies present a variety of management challenges. For example, HIV testing within the ANC/MCH setting may cause conflict between laboratory staff and $\mathrm{ANC} / \mathrm{MCH}$ staff. This may require PMTCT program managers to seek a high-level administrative decision on who carries out the HIV test. Another management challenge is defining staff roles in the client flow. Managers will need to specify which staff will carry out group pre-test counseling, HIV testing, and post-test counseling versus those who will carry out more traditional ANC functions. Another management issue is the need for adequate physical space for VCT. This will require negotiation with management of the facility and/or additional resources for space extension.

3.e. Monitoring and Evaluation: Current data from PMTCT programs frequently only shows the number of women counseled and those who get tested. PMTCT programs should expand their information system to collect and routinely report the proportion of women tested who obtain their test results. Data on disclosure to spouses should also be collected to help program managers evaluate the effect of their male involvement strategies and modify them accordingly. Furthermore, programs should evaluate new VCT strategies in a learning site before taking the approach to scale.

3.f. Policy Review or Development: Some countries may need to revise national policies on pre-test counseling to permit routine HIV testing after group counseling while guaranteeing women the right to opt out. Countries may also need to change policy to allow nonlaboratory personnel to conduct HIV tests.

3.g. Supervision: Supervisors will need to make an extra effort to ensure that the program clearly defines both the role of peer counselors and what the program expects of them. Supervisors will need to monitor systematically all staff to detect constraints and make appropriate adjustments.

3.h. Supplies: First, experts should evaluate the rapid tests used for VCT in the country. If local expertise to evaluate the tests does not exist then the country should follow the WHO list of approved HIV assays. Second, programs should seek technical assistance from logistics experts to set up systems for supplying, storing, stock checking, and restocking of the test kits and other consumables such as gloves and lancets. See below the list of useful documents on HIV test kits supplies and logistics.

\section{Cost Considerations for VCT}

Currently little data exists on the cost and cost-effectiveness of VCT specifically within the ANC setting. However, data from other settings shed some light on the range of costs. In Kenya, for example, VCT provided as part of the outpatient care of a government health center costs US\$8.24 per person tested (Lara 2002). In 1997 the AIDS Information Center in Uganda reported the cost of providing VCT at a stand alone site as US\$13.39 per client. Of this US\$5.46 was for direct services while US\$7.93 was for fixed costs, administration, supervision and monitoring (UNAIDS 1999). 


\section{I.B. Short Course Antiretroviral Drugs for PMTCT}

\section{Key Lessons}

- The ARV regimens for PMTCT are simple enough such that nurses and other qualified health workers can prescribe them in the ANC setting without problems.

- ARV uptake, defined as the proportion of HIV-positive women receiving ARVs from the PMTCT program, is still too low.

- Programs are missing many opportunities for giving ARVs in the ANC clinic, during labor, and to the newborn immediately after birth.

- Not all women receiving ARVs actually ingest them as instructed.

- Few programs have strategies for monitoring ingestion of ARV once dispensed.

\section{Recommended Program Actions for ARVs}

Giving antiretroviral drugs to pregnant, HIV-infected women can decrease the mother-toinfant transmission rate significantly by reducing transmission during pregnancy and childbirth. Based on current evidence and taking into account effectiveness, cost, and feasibility, short course zidovudine (AZT) and single-dose nevirapine are the best ARV options for prevention of MTCT in developing country settings. ${ }^{4}$ To increase uptake of the ARV drugs and to ensure that all HIV-positive mothers and their infants take the drugs as recommended requires programs to enhance counseling, strengthen links with nearby maternity services, and improve client follow-up.

\footnotetext{
${ }^{4}$ A number of clinical trials aiming to develop more efficacious regimens are underway. Thus, guidelines relating to the type of drug, dosage, and timing of ingestion will likely be updated.
} 
Table 2 Essential Components of ARV Provision

\begin{tabular}{|c|c|c|}
\hline Essential Service Component & Recommended Actions & Other Options \\
\hline $\begin{array}{l}\text { a. ARV Drug Regimens for } \\
\text { Women and their Infants }\end{array}$ & $\begin{array}{l}\text { Prescribe either short-course } \\
\text { AZT or nevirapine. }\end{array}$ & $\begin{array}{l}\text { Review new data and consider } \\
\text { a regimen which offers the } \\
\text { mother both AZT and NVP at } \\
\text { the onset of labor and infant } \\
\text { both AZT and NVP. } \\
\text { Offer HAART to pregnant } \\
\text { women who meet the } \\
\text { eligibility criteria. }\end{array}$ \\
\hline b. ARV Counseling & $\begin{array}{l}\text { Schedule a second post-test } \\
\text { counseling session for HIV- } \\
\text { positive women focusing on } \\
\text { ARVs. } \\
\text { Allow adequate time for } \\
\text { counseling on ARVs. }\end{array}$ & $\begin{array}{l}\text { Test strategy of dispensing } \\
\text { ARV during first post-test } \\
\text { counseling session if mother is } \\
\text { HIV-positive. }\end{array}$ \\
\hline $\begin{array}{l}\text { c. Promotion of Adherence to } \\
\text { ARV Regimen }\end{array}$ & $\begin{array}{l}\text { Counsel on adherence when } \\
\text { dispensing ARV. } \\
\text { Dispense full dose of AZT } \\
\text { or nevirapine, including } \\
\text { baby's syrup, at thirty-four } \\
\text { weeks. } \\
\text { For nevirapine syrup use } \\
\text { luerlock antispill syringes. } \\
\text { Monitor ingestion using } \\
\text { client reports, pill counts, } \\
\text { and weighing of syrup } \\
\text { bottles in the case of AZT } \\
\text { syrup. } \\
\text { Observe and document } \\
\text { ingestion of intrapartum } \\
\text { dose. } \\
\text { Train labor ward staff in } \\
\text { PMTCT. } \\
\text { For woman delivering away } \\
\text { from the PMTCT site, } \\
\text { encourage her to inform her } \\
\text { birth attendant of the need }\end{array}$ & $\begin{array}{l}\text { Conduct operations research to } \\
\text { test the feasibility of follow-up } \\
\text { at home to promote and } \\
\text { monitor adherence. } \\
\text { Use electronic monitoring } \\
\text { bottles or test umbilical cord } \\
\text { blood for ARV. } \\
\text { Provide nevirapine for women } \\
\text { of unknown status in labor } \\
\text { then offer rapid testing } \\
\text { postnatally to offer nevirapine } \\
\text { and AZT to newborn. }\end{array}$ \\
\hline
\end{tabular}




\begin{tabular}{|l|l|l|}
\hline Essential Service Component & Recommended Actions & Other Options \\
\hline & $\begin{array}{l}\text { for the intrapartum dose. } \\
\text { Ask mothers who deliver } \\
\text { away from the PMTCT site } \\
\text { to report to site within two } \\
\text { days of delivery. }\end{array}$ & \\
& $\begin{array}{l}\text { Disseminate guidelines on } \\
\text { ARVs for PMTCT to all } \\
\text { nearby maternity services } \\
\text { and train TBAs on PMTCT. }\end{array}$ & \\
& $\begin{array}{l}\text { Ensure that the mother has a } \\
\text { card showing that ARV } \\
\text { drugs were dispensed to her. }\end{array}$ & \\
\hline
\end{tabular}

2.a. Provide ARV drugs to Women and their Infants: Feasibility, efficacy, and cost should determine the local choice for the antiretroviral prophylactic regimen to include in the standard package of care. Considerations include the proportion of women attending antenatal care; time of initiation of antenatal care; frequency of antenatal visits; type of HIV voluntary counseling and testing available; logistics and acceptability of antiretroviral prophylaxis administration; and cost of drugs (WHO 2000).

PMTCT programs in developing countries have tended to use one or both of the following effective drug regimens.

- The first is a short-course of zidovudine (AZT). This entails 300 milligrams (mg) of AZT twice a day starting at a gestational age of thirty-six weeks and $300 \mathrm{mg}$ every three hours during labor. No drugs are taken by the mother or infant postpartum. This regimen was shown to reduce transmission during pregnancy and childbirth by 50 percent (Shaffer et al. 1999). Program experience has shown that many women deliver at or before thirty-eight weeks of pregnancy, thus giving them insufficient dosage of AZT. Thus, programs should start women on the short-course AZT therapy at thirty-four weeks of gestation.

- The second regimen uses the drug nevirapine (NVP) and is based on the results of the HIVNET 012 study. The study showed that a single $200 \mathrm{mg}$ dose of nevirapine to the mother at the onset of labor and a single dose of nevirapine (two mg per kilogram of birth weight) to the infant within seventy-two hours of birth reduced transmission of HIV during pregnancy and childbirth by 44 percent (Guay et al. 1999).

In the Ditrame Plus ANRS 1201 study in Côte d'Ivoire, pregnant women diagnosed with HIV-1 infection were treated with both zidovudine and nevirapine. Their babies also 
received both drugs. ${ }^{5}$ Out of 141 infants followed for four weeks only 8 had been infected, a transmission rate of 5.7 percent. Such findings suggest that programs should consider giving mothers both AZT and NVP at the onset of labor and giving the baby both NVP and AZT (Dabis 2002).

Where feasible, programs can provide highly active antiretroviral therapy (HAART) to pregnant women who meet the national or local eligibility criteria. WHO recommends the use of a number of ARV drugs widely used in pregnant women, including zidovudine, lamivudine (3TC), nevirapine, nelfinavir (NFV) and saquinavir (SQV) combined with low dose ritonavir. For pregnant women, it may be desirable to initiate HAART after the first trimester, although for pregnant women who are severely ill, the benefit of early therapy outweighs any potential fetal risks.

2.b. ARV Counseling: One of the main reasons for low uptake of ARV is that counseling inadequately addresses women's concerns over use of ARV for PMTCT. A major concern is felt or actual stigma. Programs should schedule all HIV-positive women for a second post-test counseling session during which the counselor can discuss ARVs. Programs should ensure that the counseling session is of adequate length to allow time for the woman to ask questions and understand the use of ARVs for PMTCT. Supporting women in their attempts to disclose their HIV status to significant others can help prevent felt stigma and build support from friends and family.

Furthermore, programs may wish to consider the possibility of testing the strategy of dispensing ARVs during this post-test counseling session (rather than waiting until thirtyfour weeks when women begin taking the drugs). This approach has the advantage of ensuring that all HIV-positive women will get ARVs. However, the strategy may not necessarily result in better ARV ingestion rates. First, mothers may not have been given enough time to think about the issue. Second, considerable time may elapse between the dispensing of the medication and the planned initiation of the ingestion. Hence, programs should first carry out this strategy in the context of operations research to observe its effect on actual ingestion before making it routine.

Country Experience: In the Demonstration of Antiretroviral Therapy (DART) Project in Soweto, South Africa, VCT counselors distribute the ARV drugs (nevirapine) during post-test counseling to women who tested positive and agreed to the intervention.

Counselors give each woman a package with written instructions together with the dose of NVP. This ensures that women are in possession of the drug at the onset of labor. Women are encouraged to return for ongoing counseling, and/or attend a support group to reinforce guidance they receive during counseling. When the HIV-infected pregnant woman returns in labor, the midwife asks if she has taken the NVP tablet. If the woman has lost it or forgotten it at home, the midwife will redispense it from the ward stock. After delivery, at the time of the BCG and polio vaccination, the baby will receive a dose

\footnotetext{
${ }^{5}$ The regimens for mothers is $300 \mathrm{mg}$ zidovudine orally twice daily initiated at or after thirty-six weeks of amenorrhea, and an oral loading dose of $600 \mathrm{mg}$ zidovudine and $200 \mathrm{mg}$ of NVP at onset of labor. The regimen for babies is one week of oral zidovudine ( $2 \mathrm{mg} / \mathrm{kg}$ every 6 hours), and a single oral dose of NVP $(2 \mathrm{mg} / \mathrm{kg})$ on day three.
} 
of NVP syrup. This current protocol modified the initial practice within the program of waiting to distribute the ARV drug to women at their antenatal visit during the thirty-fifth week. Delaying the distribution resulted in many women never receiving the tablet because they did not return, or because they delivered earlier than expected. Project managers reported positive experiences using the current approach. Of the fifty-seven HIV-positive women who received the ARV drug had delivered during the first five months of the project, 88 percent reported having successfully taken the drug (Oberzaucher and Baggaley, 2002)

2.c. Promotion of Adherence to ARV Regimen: For many women who decide to take ARVs, adherence to drug regimens remains a problem. Those on short-course AZT can miss doses before going into labor and mothers can forget to carry the intrapartum dose with them when they go to the hospital while in labor. For those mothers on the NVP regimen, not taking their dose at the right time may render the drug useless. Similarly, if their baby does not receive the NVP syrup within seventy-two hours after birth, the effect is lessened. PMTCT programs should thus make adherence a key component of drug dispensing and follow-up. As a first step, counselling should stress that adherence is primarily the responsibility of the mother. Additionally, since even in high-prevalence areas the number of HIV-positive women taking ARV within the clinic catchment area is in the hundreds, clinics may want to use home visits to follow up mothers who do not keep appointments. Staff should ask mothers who deliver away from the PMTCT site to report to the clinic within two days after birth. This will help to confirm that women use their ARVs during labor and provide the opportunity to give newborns their dosage, if already taken.

To promote adherence during labor, programs should take a number of steps. The PMTCT program should provide midwives in the labor ward with counseling skills, support and drugs to enable them to identify mothers needing ARVs and give the drugs according to the right dose. When dispensing ARVs, counselors should help mothers review their delivery plan to ensure that the intrapartum dose of ARV is part of this plan. Health workers should observe and document the ingestion of the intrapartum dose. If the woman plans to deliver away from the PMTCT site, workers should give her a referral note to ensure that her birth attendant knows of the need for the intrapartum dose and when it should be given. Even those women who plan a hospital birth should receive a card showing that ARV was dispensed to her, because transport difficulties often mean they end up giving birth at home. Programs should disseminate guidelines regarding ARV for PMTCT to all nearby maternity services and train traditional birth attendants (TBAs) in PMTCT.

Programs could monitor adherence using a number of methods such as client reports, pill counts, and weighing of syrup bottles. On an experimental basis programs could consider using electronically monitored bottles, which record every time someone opens a bottle of AZT. Measurement of ARV concentrations in the umbilical cord blood is more accurate but only helps to detect the ingestion of the intrapartum dose. Resources permitting, programs could test the feasibility and cost effectiveness of using these sophisticated means to measure adherence. 
Country Experience: In Keemba, Zambia, when a woman plans to deliver with a TBA, clinic staff invite the TBA to the health facility and educate her about PMTCT and the role and dose of ARV. When a woman goes into labor, the TBA supports the mother to take her intrapartum dose and give the baby the syrup within seventy-two hours of birth. After delivery, some TBAs escort the mother to the health facility within the first week of delivery to register the birth. This helps the program to monitor adherence to ARV by women who deliver away from the facility (Horizons 2001).

In high-prevalence countries, programs could provide nevirapine to women of unknown status who go into labor and who receive rapid HIV testing immediately after labor. If a woman is HIV-positive, the program can then supply her newborn with NVP and AZT.

Country Experience: The Kenyatta National Hospital in Nairobi offers PMTCT services to ANC women yet two-thirds of the women who deliver there do not receive antenatal care at the hospital. In a pilot study, five milliliters of cord blood were taken at delivery from a sample of women. After delivery, the program counseled 253 women of which 87 percent consented for HIV testing of cord blood. The program offered neonatal AZT and infant feeding counseling to $35 \mathrm{HIV}$-positive mothers. Of these, 17 agreed to give AZT to their babies (Inwani 2002).

\section{Systems Needs for Provision of ARVs}

3.a. Coordination: Scaling up of PMTCT programs and the use of the new ARV approaches will require strengthened coordination both at the national and site levels. For example, at the national level, to ensure a steady supply of ARVs, the many partners supporting PMTCT programs should collaborate nationally on nevirapine donation applications, importation, storage, and distribution. Locally, PMTCT sites should collaborate with nearby maternity sites and TBAs to promote intrapartum use of ARVs. This will help pregnant women who are dispensed ARVs at the PMTCT center but, for various reasons, deliver at a different maternity site. Midwives at the other maternity sites should have the means to correctly identify mothers on ARVs for PMTCT and support them in a confidential manner to take their intrapartum dose and make sure their baby receives their dose. Managers of the PMTCT sites should establish a referral and feedback network with nearby maternity sites (private, missionary, or TBAs), and ensure that workers at these sites receive training in PMTCT and know how the mother's clinical history card indicates HIV status and ARV dispensing.

3.b. Human Resources and Capacity Development: Programs should conduct PMTCT training for all health workers in the vicinity of the PMTCT center or clinic. This will help raise the odds that mothers and their infants receive and ingest the appropriate ARV dose. Programs will also need to train more health workers in PMTCT as they scale up.

3.c. Management: Management of ARV prescription and dispensing in the PMTCT context is complex and requires a multidisciplinary team approach. The different health workers involved in the prescription, dispensing, and observation of ingestion of ARV 
should meet regularly to review procedures and address problems. Managers should compare client information to ensure that dispensing and ingestion information is clear for every woman.

3.d. Monitoring and Evaluation: National PMTCT managers should improve information collected on ARV adherence. Currently, PMTCT sites typically report only ARV dispensing data and not the number of pregnant women who have actually ingested the drugs. Clinic staff should use postnatal visits to collect and compile data on ARV ingestion. Programs should encourage women who deliver away from the PMTCT site to report to the site within the first week after delivery, so as to provide information on their ARV use. The PMTCT program in Zambia has successfully used this approach with TBAs (see box above).

3.e. Policy Review or Development: PMTCT programs should seek policy support or clarification on a number of ARV-related issues. Programs should register nevirapine and AZT as essential drugs for PMTCT and develop clear policy guidelines for their use. Programs should periodically revise guidelines as new, more efficacious regimens are introduced. National programs should also develop policies that formally allow other health workers in addition to doctors to prescribe ARVs. Such a policy reduces missed opportunities that occur when a doctor is not available. Guidelines should also recognize the role of TBAs in helping mothers take the intrapartum dose.

3.f. Supervision: Patients taking ARVs need careful clinical monitoring. Although most countries only allow doctors to prescribe ARVs, trained health workers from other cadres can safely prescribe them, given that the benefits outweigh any possible clinical risks. Senior clinicians attached to or in charge of the health facilities where PMTCT services are taking place should take responsibility for the ARV component. Where managers have allowed well-trained health workers to prescribe ARVs on behalf of doctors, clinical supervision of ARV prescription and use is still needed. Moreover, senior clinicians or nursing officers should provide clinical supervision to those TBAs who help women and their infants take the drugs. As a supervision tool, $\mathrm{MCH}$ staff should complete a checklist for the first postnatal visit by mothers on the ARV regimen. This checklist should ask the woman about ARV ingestion and any drug-related side effects such as nausea and headaches. Clinic staff should also carry out a general medical examination of the mother and baby to exclude possible side effects of ARV.

Country Experience: With the establishment of the PMTCT program in Zambia, TBAs who attend deliveries of mothers on the ARV regimen accompany the mother and her baby to the health center within a week after the birth. This allows clinic staff to monitor TBA support for the PMTCT program. This approach builds on the previous system where TBAs regularly reported on the births they attended.

3.g. Supplies: Supply personnel should use current data to project quantities of adult and infant doses. They should also develop ARV procurement, storage, and distribution 
guidelines to minimize stock outs or expired drugs. When going to scale, managers should use a phased approach. First, they should integrate quantities of ARVs stocked and distributed into the regular management information system. Then they should make the effort to start to import ARVs together with other drugs. Finally, they should fully integrate ARVs with the regular drug distribution system. The ARVs must be on the Essential Drugs List and ultimately should be made available through the government system. Countries should access NVP supplies, which have a $20 \mathrm{ml}$ bottle to allow $6 \mathrm{mg}$ to be dispensed without the risk of leaving large amounts of syrup in an already opened bottle to stand exposed. Programs should also procure and supply luerlock syringes for dispensing the baby dose of nevirapine.

\section{Cost Considerations for ARV Provision}

The national program manager should develop a strategic plan of ARV acquisition, clearly stating the sources and costs of nevirapine and AZT. Currently, there are three main sources of ARV for PMTCT use in public facilities in most developing countries. The Boeringher Ingleham donation of nevirapine is being managed through Axios. In addition, UNICEF and the Elizabeth Glaser Pediatric AIDS Foundation supply ARVs. Governments should however, undertake long-term financial planning to ensure steady supplies, including seeking out available generic equivalents of high quality ARVs. At the same time programs must address issues of patents and potential changes in legislation. Then, managers should consider a variety of funding mechanisms, including revolving funds. 


\section{I.C. HIV and Infant Feeding}

\section{Key Lessons}

- Infant feeding counseling and support which address the special needs of HIV-positive women has proved to be the most demanding component of PMTCT programs. Challenges include changing the behavior of health workers and supporting women after they give birth.

- Global guidance on infant feeding exists but many recommended options are not evidence-based. Current guidance does not tell programs how to assess the feasibility, acceptability, affordability, safety, and sustainability of replacement feeding.

- Health workers frequently lack the knowledge and skills to provide infant feeding counseling and support. Counseling for HIV-positive women often promotes one feeding method over others because many of the options are either unfamiliar or unacceptable locally.

- Two of the recommended options - exclusive formula feeding and exclusive breastfeeding - are difficult for mothers to adhere to. Neither is the cultural norm and both impose complicated demands on the mother (for instance, hygienic preparation of formula or requiring that the breastfeeding mother be the only one to feed her infant). PMTCT programs do not sufficiently assess and address the need for community-based support to deal with sociocultural and other barriers to adherence.

- Scarcely any program experience documentation exists for developing practical guidelines and supporting mothers to cease breastfeeding abruptly.

- HIV-positive mothers appreciate the counseling they receive on infant feeding and report that the counseling has helped them understand why their feeding choice is the best one for them and their baby.

\section{Recommended Program Actions for Infant Feeding}

To maximize the likelihood that infants of HIV-infected women survive and are free of HIV, PMTCT programs need to revitalize and expand initiatives that support good infant and young child feeding for all children. Inside the PMTCT clinic, programs should offer high-quality counseling on infant feeding and HIV for HIV-positive women, and put in place mechanisms for follow up and support of infant feeding practices, breast health, and maternal nutrition in the postpartum period. 
Table 3 Essential Components for HIV and Infant Feeding

\begin{tabular}{|c|c|c|}
\hline $\begin{array}{l}\text { Essential Service } \\
\text { Component }\end{array}$ & Recommended Actions & Other Options \\
\hline $\begin{array}{l}\text { a. Promotion of Appropriate } \\
\text { Infant and Child Feeding } \\
\text { Practices in Health Centers and } \\
\text { Communities }\end{array}$ & $\begin{array}{l}\text { Promote good feeding } \\
\text { practices for all women and } \\
\text { children. } \\
\text { Advocate for the Baby- } \\
\text { Friendly Hospital Initiative } \\
\text { as a strategy that promotes } \\
\text { feeding choices appropriate } \\
\text { to every mother's situation. } \\
\text { Organize home visits, peer } \\
\text { counseling, and mother } \\
\text { support groups for the first } \\
\text { weeks after delivery. }\end{array}$ & $\begin{array}{l}\text { Encourage the participation of } \\
\text { the extended family, including } \\
\text { partners, grandmothers, and } \\
\text { in-laws. }\end{array}$ \\
\hline $\begin{array}{l}\text { b. Counseling on Infant Feeding } \\
\text { and HIV }\end{array}$ & $\begin{array}{l}\text { Begin infant counseling } \\
\text { during antenatal care. } \\
\text { Counsel women based on } \\
\text { local guidelines adapted } \\
\text { from international } \\
\text { standards. In adapting } \\
\text { guidelines, use local } \\
\text { assessments of feasibility, } \\
\text { acceptability, affordability, } \\
\text { safety, and sustainability of } \\
\text { replacement feeding. } \\
\text { Discuss replacement } \\
\text { feeding only after HIV } \\
\text { testing. } \\
\text { Discuss signs of breast } \\
\text { pathology, implications for } \\
\text { transmission, and the need } \\
\text { to seek prompt treatment. } \\
\text { Offer multiple sources of } \\
\text { counseling and support such } \\
\text { as the ANC nurse, peer } \\
\text { counselors, lactation } \\
\text { counselors in the maternity } \\
\text { ward, and community } \\
\text { mothers groups. }\end{array}$ & $\begin{array}{l}\text { During health education and } \\
\text { pretest counseling discuss } \\
\text { appropriate replacement } \\
\text { feeding options within the } \\
\text { context of cultural practices in } \\
\text { the country. } \\
\text { Where feasible, link with } \\
\text { community organizations. }\end{array}$ \\
\hline
\end{tabular}




\begin{tabular}{|c|c|c|}
\hline $\begin{array}{l}\text { Essential Service } \\
\text { Component }\end{array}$ & Recommended Actions & Other Options \\
\hline $\begin{array}{l}\text { c. Nutritional Support for Infants } \\
\text { who are not Breastfed }\end{array}$ & $\begin{array}{l}\text { Procure and provide } \\
\text { formula and or a local infant } \\
\text { food for replacement } \\
\text { feeding according to } \\
\text { national guidelines } \\
\text { Procure and provide locally- } \\
\text { produced, nutritionally } \\
\text { appropriate weaning foods } \\
\text { according to national } \\
\text { guidelines }\end{array}$ & \\
\hline d. Postnatal Follow-up & $\begin{array}{l}\text { Treat breastfeeding mothers } \\
\text { for mastitis and other } \\
\text { systemic infections. } \\
\text { Discuss with the mother the } \\
\text { availability of appropriate } \\
\text { weaning foods. } \\
\text { Strengthen postnatal follow- } \\
\text { up by using outreach and } \\
\text { support groups to help } \\
\text { mothers safely apply their } \\
\text { infant feeding decision, } \\
\text { encouraging good maternal } \\
\text { nutrition, and addressing } \\
\text { infant feeding after six } \\
\text { months. }\end{array}$ & \\
\hline
\end{tabular}

2.a. Promotion of Appropriate Infant and Child Feeding Practices in Health Centers and Communities: National PMTCT programs should intensify efforts to promote good lactation and nutritional practices for all women and children, with HIV and infant feeding considered as a special case. PMTCT programs should advocate for strengthening overall antenatal care and infant feeding practices, specifically for efforts such as the Baby-Friendly Hospital Initiative (BFHI) as a strategy that promotes feeding choices appropriate to every mother's situation. The BFHI aims to ensure that every facility providing maternity services and care for newborn infants applies the "Ten Steps to Successful Breastfeeding" to ensure that women receive optimal support for breastfeeding. The BFHI is consistent with the special needs of HIV-positive women. Step six of the ten steps states: "Give newborn infants no food or drink other than breast milk, unless medically indicated." This means that if a mother is HIV-positive, it is an accepted medical indication that she not breastfeed her infant. Step ten, "Foster the establishment of breastfeeding support groups and refer mothers to them on discharge from hospital or clinic," is relevant for generating community support and reducing stigma. 
Managers should review the status of the International Code of Marketing of Breastmilk Substitutes in their countries, and take appropriate action to implement it. If countries have not put in place measures giving effect to the Code, program official should seek support from WHO and UNICEF to draft and implement such regulations, which should include provisions for effective monitoring and enforcement and for sanctions. Managers should also ensure that health care workers know about their responsibilities under the Code, understand its continuing relevance in the context of HIV, and apply it in their work.

Peer counseling and social support in general have a positive effect on the initiation of breastfeeding, giving colostrum, and exclusive breastfeeding. Home visits in particular appear to play a central role in supporting healthy breastfeeding behaviors and are associated with longer durations of exclusive breastfeeding. Mothers visited more frequently are more likely to adopt recommended behaviors than those visited less often or not at all.

Country Experience: Good hospital practices can promote healthy breastfeeding behaviors in the first weeks after birth. These include rooming-in, early mother-infant contact and avoiding giving infants food before they begin breastfeeding. Studies in settings as diverse as Brazil, India, Indonesia, Nicaragua, Panama, and Peru found that changes in hospital practices and training hospital workers increases the prevalence or duration of exclusive breastfeeding (Green 1999). A study in Mexico found that women receiving six visits from a peer counselor have higher rates of exclusive breastfeeding at three months postpartum than those who received three visits or were not visited at all (Morrow et al. 1996).

2.b. Counseling on HIV and Infant Feeding: PMTCT programs should recommend exclusive breastfeeding as the only feeding practice for those mothers who know they are uninfected or for those not aware of their HIV status. For HIV-positive women, programs should recommend replacement feeding only when such feeding is affordable, feasible, acceptable, sustainable, and safe. Counseling for HIV-positive women on replacement feeding should be based on local guidelines adapted from international standards.

It is preferable that counselors discuss replacement feeding only after HIV testing. Alternatively, during pretest counseling attended by all women, counselors can discuss the risk of transmission during breastfeeding and possible strategies for minimizing that risk, including replacement feeding. If programs choose the latter approach, they will need to monitor whether this strategy results in any "spillover," that is, whether they are inadvertently causing non-infected mothers to choose less healthy infant feeding practices. 


\section{Conducting a Local Assessment of Infant Feeding Knowledge, Practice, and Options}

An assessment of infant feeding options should include the participation of health workers, outreach workers, community leaders and members, and communication specialists. The assessment should:

- Measure current levels of knowledge, understanding, and practice of the infant feeding options among different groups of mothers and community members. This will increase understanding of information gaps, rumors, myths and misconceptions for different groups (for example the prevalence of water supplementation instead of exclusive breastfeeding) and yield recommendations for practices to reinforce and changes to facilitate.

- Identify the perceived benefits and costs of the different infant feeding options for HIV-infected women and for women who are not infected or do not know their status. Questions should focus on the social and cultural contexts and norms that shape women's choices, including the key social groups - the family and community - that influence adherence to their choice.

- Identify credible sources and charismatic promoters of health and nutrition, infant and young child feeding, and HIV information, skillbuilding and support.

Counseling should help women put into practice their selected feeding method, and include information on the mechanics of exclusive breastfeeding and abrupt weaning or preparing replacement foods; coping with the practical, emotional, and social issues of their choice; maintaining good breast health; and maternal nutrition. When a mother opts for replacement feeding, counselors should assess and support her knowledge of dangers, signs and symptoms of dehydration and of oral rehydration therapy.

Country Experience: PMTCT programs that promote replacement feeding for HIVpositive mothers may inadvertently cause non-infected mothers to choose less healthy infant feeding practices. To minimize the possibility of this negative "spillover effect," PMTCT counselors in Honduras provide information on replacement feeding only during post-test counseling for HIV-positive women. Counselors encourage HIV-negative women to breastfeed exclusively, and deliberately do not mention that the program distributes infant formula for HIV-positive mothers. Key informants report that this strategy appears to have introduced infant formula for women with known HIV infection without adversely affecting the potential of other women to breastfeed exclusively. (Source: Baek, Rodriguez, and Escoto, 2002)

PMTCT programs should maximize the number of sources of counseling and support for infant feeding. At the antenatal clinic, nurse or midwife counselors should initiate discussions about infant feeding and peer counselors should help women sort through the 
advice they receive and assess it in light of the realities of their life. In hospital maternity wards, lactation counselors should help mothers at the critical moment when infant feeding begins. Where feasible, PMTCT programs should also link with community organizations to assist with infant feeding counseling and support. This includes, where shared confidentiality permits, encouraging influential family members (partners, grandmothers, aunts, etc.) to respect a mother's decision to breastfeed exclusively.

Country Experience: A study in high HIV prevalence areas of urban Zambia is looking at whether enhanced counseling can effectively promote exclusive breastfeeding and abrupt weaning at four months. Group prenatal education/counseling in the PMTCT sites emphasizes the importance of exclusive breastfeeding, including for nutrition and protection against infection other than HIV; the risks associated with giving infants additional food or liquid; and addressing common problems associated with exclusive breastfeeding. In one-on-one sessions, counselors review a woman's infant feeding practices, encourage good practices, suggest changes in harmful practices, and recommend strategies to overcome likely barriers to exclusive breastfeeding. After delivery, counselors reinforce messages from prenatal counseling, ensure that breastfeeding is satisfactorily initiated, help mothers to identify and solve early difficulties, and encourage women to continue exclusive breastfeeding. The program also employs a hospital-based lactation counselor and community health workers. Preliminary results show the program helps a significant proportion of women adhere to exclusive breastfeeding (Kuhn 2002).

2.c. Nutritional Support for Infants who are not Being Breastfed: Programs that decide to provide replacement food for HIV-positive mothers should procure formula and/or a local infant food in accordance with the International Code of Marketing of Breastmilk Substitutes and World Health Assembly resolutions. Similarly, where national policy guidelines include the choice of exclusive breastfeeding for a short period (for example, three or four months) and then abrupt weaning, PMTCT programs may consider procuring and providing a nutritionally appropriate, locally available weaning food.

2.d. Postnatal Follow-up: Clinic and community services should support mothers feeding young children. Clinical services should include immediate treatment for mastitis and other systemic infections that affect HIV viral load in breastmilk and account for a sizeable fraction of postnatal transmission, particularly in the early months postpartum. To encourage women to adhere to good feeding practices, PMTCT programs should support activities that mobilize partner, family, and community support for infant feeding such as outreach activities and support groups. 
Country Experience: A project working with HIV-positive mothers in Zimbabwe found that establishing a support group for couples facilitates communication around sensitive issues. Among the most frequently discussed issues is how to explain alternative methods of infant feeding to members of their extended family. The support group makes it easier for couples to discuss such issues and allows couples to examine various effective strategies and to take joint decisions. As a result they are better able to withstand pressure from the extended family to adopt traditional feeding practices that may be inappropriate given their HIV status (Karemba 2002).

\section{Systems Needs for Infant Feeding Counseling and Support}

3.a. Coordination: A national focal point on infant feeding and HIV should be appointed to facilitate coordination between sectors and between PMTCT and other programs. The coordinator should be a member of the national infant feeding coordinating group, if one exists. PMTCT programs should advocate for stronger overall counseling on infant and young child feeding as part of maternal-child health services. National programs should develop terms of reference to facilitate linkages with various programs such as the BabyFriendly Hospital Initiative, safe motherhood, antenatal care, Integrated Management of Childhood Illness, and family planning.

3.b. Human Resources and Capacity Development: PMTCT programs should train all health workers who are counseling pregnant women about infant feeding in breastfeeding promotion, the International Code of Marketing of Breastmilk Substitutes, and steps to successful breastfeeding. Training on infant feeding and HIV should encourage lactation management skills to promote and protect good breastfeeding practice. As part of staff capacity building, the PMTCT program should document challenging situations and how women handle them. Counselors can share these experiences with other women to suggest ways women can explain and manage their feeding choice. Counselor training should include role-playing that gives counselors practice in handling difficult questions and situations.

Pre-service and in-service training for doctors, nurses, community health workers, and lay counselors should include instruction on infant feeding counseling. For in-service training, improvements could include adding an additional week to the PMTCT minimum package of training for $\mathrm{MCH}$ staff, or adding refresher or separate training for infant feeding counselors.

Programs should obtain and adapt existing job aids or develop new ones to include scripts and flow charts to standardize key counseling messages and enhance the skills of counselors and other clinic staff (See appendix A. Useful Documents).

Country Experience: In Botswana, PMTCT counsellors are required to do an additional two week course on infant and young child feeding counselling (Programme Review Team 2002). The Kenya PMTCT curriculum devotes one of five modules to lactation management. The curriculum introduces information on infant feeding choices for the 
HIV-infected mother only after describing and reinforcing good breastfeeding practice (Kenya PMTCT Project 2002).

3.c. Monitoring and Evaluation: For monitoring, programs must collect data on the quantity and quality of infant feeding counseling at the clinic or other service site.

Programs can measure the quantity of infant feeding counseling through a counseling register and through client interviews and gauge quality via observation of infant feeding counseling sessions, interviews with clients, and the use of mystery clients. This information is critical to help managers know whether their program is appropriately and fully using training, job aids, and other inputs.

Programs also need data to evaluate the impact of infant feeding counseling on client practices. Evaluation should include information on feeding choice, the degree to which mothers correctly practice their choice, breast health and other maternal health problems, care-seeking behavior, and infant growth, sickness, and death. Having good data on why clients do not comply with exclusive feeding choices will be central to both resolving the problems of individual mothers and to reorienting program efforts.

3.d. Policy Review or Development: The national PMTCT coordinating body should draft or revise national policy guidelines to reflect current and local knowledge on infant and child feeding practices generally, and specifically in relation to HIV. National programs should adapt international guidelines through assessment and dialogue to simplify and narrow options. National policy guidelines should only include feeding options that are feasible and realistic. The International Code of Marketing of Breastmilk Substitutes and the BFHI offer important protection for infant feeding choice and breastfeeding and thus should be highlighted in national policy. To avoid confusion among health workers and clients, national programs should review and update infant feeding guidance not more frequently than once every two years.

As part of the development of guidelines, programs should observe the organization of services and the flow of clients - in particular examining at what point women learn their HIV status - to determine when best to include infant feeding education and counseling.

Country Experiences: Researchers in Zambia helped to develop locally appropriate and feasible infant feeding recommendations for HIV-positive and HIV-negative mothers and their families. The research team consisted of members of the National Food and Nutrition Commission, the health management team of the district where a pilot project was planned, nurse-midwives in charge of two health centers, and staff from the USAIDfunded LINKAGES and SARA projects. The three-month study included focus group discussions, key informant interviews, observation of household food preparation and feeding practices, a market survey of locally available replacement foods and breastmilk substitutes, and household trials of improved feeding and caring practices (Source: National Food and Nutrition Commission (Zambia) et al., 1999)

3.e. Supplies: If the national policy supports the procurement and distribution of infant formula, the PMTCT program needs to assess and closely monitor formula requirements 
and stocks to ensure steady supplies and to minimize waste. Programs should procure supplies in compliance with the International Code of Marketing of Breastmilk

Substitutes, with special emphasis on open procurement and avoiding reliance on free or subsidized donations.

\section{Cost Considerations for Infant Feeding}

Purchasing and providing formula can add substantially to the costs of a PMTCT program. For example, a study in Mozambique estimated that providing formula for a population of 9283 pregnant women in the city of Chimoio would cost US\$100,417 (the cost of formula plus four counseling sessions) per year. When the investigators modeled the overall cost-effectiveness of a PMTCT program including infant formula, they concluded that the cost per disability-adjusted life-year of including breastmilk replacements is under US $\$ 40$ (Peffer, Osman, and Vaz 2002). Although this places it within the range of interventions considered cost-effective in low-income countries, paying for the large volumes of formula needed for a nationwide program will still require a significant outlay. 


\section{I.D. Male Involvement and Support}

\section{Key Lessons}

- In most countries, male involvement and support is critical to improving women's uptake of core PMTCT services including the decision to test; returning for test results; correctly taking ARV drugs; and choosing and carrying out an infant feeding method.

- Male involvement and support are also vital for primary prevention of HIV and avoiding unintended pregnancy.

- Although it is difficult to engage men, once they do get involved, they may be very supportive.

- Despite the key role of men and the experience of family planning and other reproductive health programs in this area, PMTCT programs to date have done relatively little to involve men.

- $\mathrm{ANC} / \mathrm{MCH}$ clinics are women's spaces that cannot be easily adapted to accommodate men.

\section{Recommended Program Actions for Male Involvement}

PMTCT programs should promote male involvement by addressing community-wide beliefs and norms that often limit such involvement. Such efforts are most effective when programs communicate directly to men or indirectly through influential community leaders. Programs should, whenever possible, link with existing male involvement efforts working at the community level. Couples counseling can reach men within the ANC clinic walls, and PMTCT clinics should institute referral programs to encourage male partners to seek VCT at alternative sites. Program should, however, be careful to avoid blaming men or to reinforce their dominant role in decision-making within the couple. 
Table 4 Essential Components for Male Involvement

\begin{tabular}{|c|c|c|}
\hline $\begin{array}{l}\text { Essential Service } \\
\text { Component }\end{array}$ & Recommended Actions & Other Options \\
\hline $\begin{array}{l}\text { a. Community-wide Information, } \\
\text { Education, and Communication }\end{array}$ & $\begin{array}{l}\text { Speak with male } \\
\text { community leaders about } \\
\text { PMTCT. } \\
\text { Offer PMTCT information } \\
\text { where men congregate such } \\
\text { as sports clubs, football } \\
\text { fields, taxi and bus stands, } \\
\text { and bars. } \\
\text { Reach men through media } \\
\text { campaigns, e.g. radio. } \\
\text { Link with existing programs } \\
\text { promoting male } \\
\text { involvement in reproductive } \\
\text { health. } \\
\text { Include messages about } \\
\text { primary prevention of HIV } \\
\text { and prevention of } \\
\text { unintended pregnancy in } \\
\text { HIV-positive women. }\end{array}$ & $\begin{array}{l}\text { Include innovative activities to } \\
\text { address traditional } \\
\text { expectations about gender. }\end{array}$ \\
\hline b. Couples Counseling & $\begin{array}{l}\text { Offer couples counseling } \\
\text { during regular clinic hours. } \\
\text { Adapt counseling to address } \\
\text { men's interests and needs. }\end{array}$ & $\begin{array}{l}\text { Offer weekend couples } \\
\text { counseling at ANC clinic. }\end{array}$ \\
\hline c. Referral for $V C T$ & $\begin{array}{l}\text { Give referral slips to women } \\
\text { to give to their partners for } \\
\text { VCT at another site. }\end{array}$ & \\
\hline d. Programs for Young Men & $\begin{array}{l}\text { Integrate fatherhood and } \\
\text { PMTCT in young men } \\
\text { programs. } \\
\text { Target young fathers while } \\
\text { they wait for childbirth. }\end{array}$ & \\
\hline
\end{tabular}

2.a. Community-wide Information, Education, and Communication: As part of the overall communication strategy, programs should provide information about PMTCT directly to men of reproductive age and work through influential male community leaders such as church leaders, village chiefs, and traditional healers. Also, programs should offer PMTCT information in locales where men congregate such as bars, football fields, and 
taxi stands. Information can be given interpersonally and through written materials. Programs should tailor the topics and messages for men, using formative evaluation and audience research. Values clarification exercises can help men to be conscious of and to address their attitudes - both helpful and harmful.

\section{Country Experience: In Keemba, Zambia more than 40 percent of male partners of} women in the PMTCT program have undergone HIV counseling and testing. In addition to the general strategy of community mobilization strategy, program staff talk about PMTCT directly with male leaders rather than through women. They also listen to the men's concerns. For example, one community leader was worried about the risk of HIV infection for himself, his wives, and his sons, and asked the staff from the PMTCT program to give a talk to his extended family. He and a number of his wives subsequently came for VCT. Several other men and their wives later followed his lead and got tested. A number of facilities in the area provide VCT, including the outpatient clinic, which provides men with comfortable access to VCT, the antenatal clinic to which they send their pregnant wives, and rural health posts during outreach visits using rapid tests. (Mutunda et al. 2001).

From the outset, Kenya PMTCT program managers identified the need to involve male partners as a critical program element. Strategies for informing male partners about PMTCT services and encouraging their support include inviting men to the clinic for HIV counseling and testing, community education on PMTCT in places where men congregate, and support groups for men. These strategies led to a significant increase in discussions about VCT and PMTCT between PMTCT clients and their regular partners, HIV testing among male partners of PMTCT clients, and disclosure of HIV results by both women and men to a regular partner (Rutenberg et al. 2002).

In addition to speaking directly with men, programs should use mass media to encourage male involvement and support for PMTCT programs. This may include sensitizing and educating journalists, radio speakers, and other media figures about PMTCT issues.

Country Experience: Recognizing the popularity of radio in rural areas and the high value that people attach to topics heard on the radio, the PMTCT program in the Thyolo region of Malawi briefed radio personalities about PMTCT (Buhendwa 2002).

Existing programs aim to increase male knowledge and support for reproductive health care more generally. PMTCT programs should link with such efforts to ensure they transmit PMTCT-relevant messages such as primary prevention of HIV and avoidance of unintended pregnancy in HIV-positive women. Community mobilization should include innovative communication activities such as dramas aimed at changing norms that promote male dominance.

2.b. Couples Counseling: Programs should offer couples counseling as an option during regular ANC clinic hours. Couples counseling sessions should take into consideration the needs and questions of both men and women. 
Country Experience: In a study of couples counseling at ANC clinics in Zimbabwe, couples received health talks and counseling on issues such as general family welfare and support, pregnancy, relationships, couple communication, and HIV and other sexually transmitted infections (STIs). Couples attended up to three counseling sessions. The couples participating in the study reported more confidence in talking about their relationships, HIV and other STIs, and condom use, and were better able to deal with unfaithful partners (Tongoona et al. 2002).

Alternatively, programs can counsel couples at times more convenient for men such as on the weekend.

Country Experience: The Zambia Exclusive Breastfeeding Study started a couples counseling clinic on Saturday mornings that significantly increased male involvement in the PMTCT program. To encourage men to undergo VCT, male community outreach workers approach women in the clinic waiting room to offer assistance in engaging their partners. Women who agree to participate arrange for the outreach workers visit their husbands at home and invite them to attend VCT. The strategy, although requiring a significant reorientation of antenatal services and more human resources, helped to increase the numbers of couples counseled ten-fold to about 55 per month (Shutes et al. 2002).

2.c. Referral for VCT: For the majority of men unlikely to visit the ANC clinic, PMTCT programs should offer referrals to other more "men-friendly" VCT sites. The PMTCT program should give the referral slip to the woman to pass to her partner.

Country Experience: In India, the PMTCT program gives women a VCT referral slip so that her husband can learn about and go to the general population VCT center (Sarna 2002).

2.d. Programs for Young Men: PMTCT programs should link with existing youth programs to encourage young men to be responsible fathers, including learning about PMTCT. Currently, reproductive health programs focus on young mothers and neglect young men. One way to reach young fathers is to educate them at the birthing center as they wait for their partners to give birth. Although of limited value to the health of their newborn, such educational activities can support primary prevention of HIV and avoid future unintended pregnancies.

Country Experience: The Papai (Daddy) project, in Recife, Brazil, hopes to educate young men about reproductive health and expand their culturally-limited role in childrearing. The project has developed a range of educational resources and print and mass media materials aimed at adolescent fathers. In addition, project staff work individually with young, unmarried fathers as they await the birth of their child at the hospital. The one-on-one contact has proved particularly successful and fewer young men have gone on to father more children (UNAIDS 2001).

\section{Systems Needs for Male Involvement}


3.a. Coordination: Linking with an existing male involvement program requires coordination with their program staff. Coordination may need to take place at different levels and possibly require advocacy in order to include PMTCT messages.

3.b. Human Resources and Capacity Development: Getting information directly to men requires recruiting and training of outreach workers. Programs should ensure that counselors have the required skills to offer effective couples counseling.

3.c. Management: The community outreach component may place a substantial burden on management. If programs choose such an approach, they should plan for extra management time and resources.

3.d. Policy Review or Development: If the PMTCT program decides to offer weekend counseling, there must change clinic hours.

3.e. Supervision: Supervisors will have the added responsibility of supervising the couples counseling component and providing technical support to counselors. Supervision will also be needed for the community outreach component.

3.f. Supplies: Referral slips should be made available. IEC materials for men should also be available.

\section{Cost Considerations for Male Involvement}

To keep clinics open on weekends for couples counseling, programs will need additional resources to compensate workers. Developing a community outreach program will also require additional outlay for recruiting, training, and expanded management and supervision tasks. Mounting a mass media campaign aimed at men will entail substantial costs.

\section{Services to be Strengthened by PMTCT Programs}

Effective prevention of mother-to-child-transmission of HIV/AIDS requires a fourpronged approach that includes primary prevention of HIV, prevention of unintended pregnancy in HIV-infected women, interventions for the prevention of MTCT from HIVinfected women, and care and support for HIV-infected infants and women.

All of these elements are critical, but PMTCT programs, which typically operate within the administrative and service framework of existing $\mathrm{MCH}$ programs, need to be cautious about trying to do too much. They lack the budget, organizational structure, and technical expertise to provide directly the full range of prevention and care interventions that make PMTCT effective. 
A reasonable expectation is that PMTCT programs directly provide selected new interventions which prevent MTCT from HIV-infected women. These are described in detail in the previous chapter.

At the same time, PMTCT programs must work to strengthen and complement existing $\mathrm{MCH}$ and HIV-related efforts. These include:

- $\quad$ primary prevention of HIV;

- antenatal care;

- safe labor and delivery;

- family planning; and

- HIV care and support for women, partners, and children.

Table 5 summarizes the recommended actions to adequately address these services, organized according to three broad approaches:

Service integration and referral. PMTCT programs should address multiple service components or health-related needs within the service environment in two ways: (1) by adding on services to existing maternal-child health and HIV interventions, either within the ANC clinic (for example, distribution of condoms for primary HIV prevention during antenatal care) or outside the clinic walls (for example, organizing support groups in the community for HIV-negative women to promote protective behavior); and (2) through referrals to other groups or organizations with specific expertise or resources (for example, referring HIV-positive mothers and their infants to groups that provide specialized clinical care).

Linkages with other programs. PMTCT programs should link with other relevant programs such as HIV behavior change communication, safe motherhood, family planning, and HIV care and support to ensure that messages for clients and health workers are consistent across programs and those programs are supporting the PMTCT program with appropriate, accessible services.

Advocacy. Advocacy is a set of targeted actions directed at decision-makers in support of a specific policy issue. PMTCT programs should employ advocacy to improve the overall environment for HIV-related care. For example, PMTCT programs alone cannot address the many structural factors - including poor motivation, and staff and materials shortages - that limit access to HIV-related care in the public sector. However, advocates for PMTCT can join with others through networks and advocacy campaigns to improve overall policies and increase allocation of resources for health programs. 
Table 5 Recommended Actions for PMTCT Programs to Strengthen Key MCH and HIV Services

\begin{tabular}{|c|c|c|c|}
\hline \multirow[b]{2}{*}{ Key Service } & \multicolumn{3}{|c|}{ Type of Approach } \\
\hline & $\begin{array}{l}\text { Service Integration and } \\
\text { Referral }\end{array}$ & $\begin{array}{l}\text { Linkages with Other } \\
\text { programs }\end{array}$ & Advocacy \\
\hline A. Primary HIV Prevention & 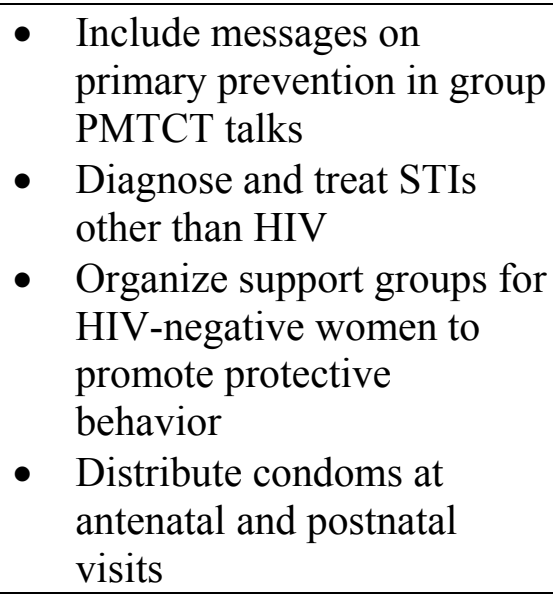 & $\begin{array}{l}\text { Work with HIV behavior } \\
\text { change communication } \\
\text { campaigns to include } \\
\text { messages about risks and } \\
\text { prevention of MTCT, as } \\
\text { another reason for behavior } \\
\text { change } \\
\text { - Include PMTCT in youth } \\
\text { HIV life skills education } \\
\text { programs }\end{array}$ & $\begin{array}{l}\text { Advocate for prevention } \\
\text { programs to address risky } \\
\text { behaviors, especially in } \\
\text { youth and men }\end{array}$ \\
\hline B. Antenatal Care & $\begin{array}{l}\text { - Offer comprehensive ANC } \\
\text { to improve the health of all } \\
\text { mothers, increase } \\
\text { acceptability of the PMTCT } \\
\text { program, and contribute to } \\
\text { reducing vertical } \\
\text { transmission rates } \\
\text { - Make each ANC contact an } \\
\text { opportunity to address } \\
\text { MTCT }\end{array}$ & $\begin{array}{l}\text { Work with central supply } \\
\text { system to ensure a steady } \\
\text { stream of all ANC supplies } \\
\text { - Seek partnerships to } \\
\text { provide nutritional support } \\
\text { for pregnant women } \\
\text { - Focus on fewer but higher } \\
\text { quality ANC visits }\end{array}$ & $\begin{array}{l}\text { - Advocate for expanded } \\
\text { access to free or low cost } \\
\text { ANC } \\
\text { - } \\
\text { Require PMTCT donors to } \\
\text { support all elements of } \\
\text { antenatal care }\end{array}$ \\
\hline
\end{tabular}




\begin{tabular}{|c|c|c|c|}
\hline \multirow[b]{2}{*}{ Key Service } & \multicolumn{3}{|c|}{ Type of Approach } \\
\hline & $\begin{array}{l}\text { Service Integration and } \\
\text { Referral }\end{array}$ & $\begin{array}{l}\text { Linkages with Other } \\
\text { programs }\end{array}$ & Advocacy \\
\hline $\begin{array}{l}\text { C. Safe Labor and Delivery } \\
\text { Practices }\end{array}$ & $\begin{array}{l}\text { - Adopt improved obstetric } \\
\text { practices which reduce } \\
\text { infant exposure to infected } \\
\text { maternal blood and other } \\
\text { fluids } \\
\text { - Provide universal } \\
\text { precautions for health } \\
\text { workers }\end{array}$ & $\begin{array}{l}\text { - } \\
\text { - } \\
\text { Review and blood supply } \\
\text { service obstetrical curricula } \\
\text { for MTCT } \\
\text { - } \text { Review and update safe } \\
\text { motherhood programs and } \\
\text { policies for attention to } \\
\text { HIV and MTCT } \\
\text { Train TBAs on the } \\
\text { contribution of improved } \\
\text { obstetrical practices to } \\
\text { preventing MTCT and } \\
\text { reducing their own risk of } \\
\text { exposure to HIV }\end{array}$ & $\begin{array}{l}\text { Advocate for policies and } \\
\text { programs to increase the } \\
\text { proportion of births } \\
\text { attended by trained heath } \\
\text { personnel at health facilities }\end{array}$ \\
\hline D. Family Planning & $\begin{array}{l}\text { - Create a seamless } \\
\text { integration between } \\
\text { PMTCT and family } \\
\text { planning services by jointly } \\
\text { addressing these needs at } \\
\text { each client contact } \\
\text { - Offer counseling for HIV- } \\
\text { infected women that } \\
\text { addresses sexuality and } \\
\text { their reproductive needs } \\
\text { and rights }\end{array}$ & $\begin{array}{l}\text { Cover risk of vertical } \\
\text { transmission in family } \\
\text { planning counseling } \\
\text { - Address risk of pregnancy } \\
\text { in infant feeding counseling }\end{array}$ & $\begin{array}{l}\text { Advocate for HIV } \\
\text { counseling and testing to be } \\
\text { part of family planning } \\
\text { services } \\
\text { Advocate for policies and } \\
\text { programs to increase access } \\
\text { to family planning for all } \\
\text { men and women, regardless } \\
\text { of HIV status }\end{array}$ \\
\hline
\end{tabular}




\begin{tabular}{|c|c|c|c|}
\hline \multirow[b]{2}{*}{ Key Service } & \multicolumn{3}{|c|}{ Type of Approach } \\
\hline & $\begin{array}{l}\text { Service Integration and } \\
\text { Referral }\end{array}$ & $\begin{array}{l}\text { Linkages with Other } \\
\text { programs }\end{array}$ & Advocacy \\
\hline $\begin{array}{l}\text { E. Care and Support for } \\
\text { HIV-Positive Women, } \\
\text { Partners and Children }\end{array}$ & $\begin{array}{l}\text { Offer follow-up counseling } \\
\text { and psychosocial support } \\
\text { using peer counselors } \\
\text { - Provide cotrimoxazole and } \\
\text { TB prophylaxis, infant and } \\
\text { maternal nutrition support, } \\
\text { and psychosocial support } \\
\text { - Refer to comprehensive } \\
\text { HIV/AIDS clinical care for } \\
\text { mother and infant } \\
\text { Refer for community-based } \\
\text { psychosocial and material } \\
\text { support }\end{array}$ & $\begin{array}{l}\text { Integrate pediatric } \\
\text { HIV/AIDS diagnosis and } \\
\text { care into Integrated } \\
\text { Management of Childhood } \\
\text { Illness (IMCI) } \\
\text { Coordinate with existing } \\
\text { NGOs and CBOs providing } \\
\text { care and support. This } \\
\text { should include NGOs and } \\
\text { CBOs providing support for } \\
\text { OVC. }\end{array}$ & $\begin{array}{l}\text { - Advocate for giving priority } \\
\text { to HIV-positive women for } \\
\text { HIV/AIDS clinical care } \\
\text { including ARVs } \\
\text { - Advocate for reduction of } \\
\text { stigma towards HIV- } \\
\text { positive people including } \\
\text { mothers who are not } \\
\text { breastfeeding }\end{array}$ \\
\hline
\end{tabular}




\section{II.A. Primary HIV Prevention}

Primary prevention of HIV is a major challenge requiring the efforts and resources of many programs and agencies. PMTCT programs can contribute by integrating primary prevention within the PMTCT services offered in the antenatal and maternal-child health setting, diagnosing and treating STIs other than HIV, coordinating prevention and PMTCT messages with other prevention programs, and advocating for prevention activities that have the greatest potential impact on women such as prevention to reduce risky sexual behavior, especially in men and young people.

\section{Service integration and referral}

HIV prevention messages and condom availability should be a part of routine PMTCT services. The daily group talks are an excellent opportunity for HIV education and to talk about prevention and behavior change. Programs should view VCT primarily as a prevention opportunity rather than as a mechanism to identify HIV-positive women who can benefit from interventions to reduce vertical transmission of HIV. Individual pre- and post-HIV test counseling sessions are a good chance to address risk and risk reduction strategies. Programs can offer peer or support groups for HIV-negative women to assist them to develop and put into practice risk reduction strategies such as condom use, mutual monogamy, and condom use with outside partners. ANC and $\mathrm{MCH}$ clinics should make condoms freely available and suggest to women that couples should practice safe sex during pregnancy and the post-partum period to protect the infant from being affected by sexually transmitted infections, including HIV.

The ANC setting is also an excellent opportunity to screen for and treat STIs. Management of STIs will immediately improve the mother's health as well as contribute to the reduction in HIV transmission.

\section{Linkages with other programs}

In addition to incorporating primary prevention messages and supportive activities into the PMTCT services, the PMTCT program should seek linkages with existing communication resources at the national and community levels to ensure that they integrate PMTCT prevention in their activities. Such linkages will inform the general population about the mother-to-child mode of transmission and promote safe sex-both for the health of the individual and for the well being of their future family. Where necessary, PMTCT programs could use their resources to help existing communication channels expand their scope and reach a wider audience with integrated messages. Programs should identify and establish collaboration with NGOs and community-based organizations (CBOs) involved in community mobilization to ensure that such organizations address all four prongs of PMTCT. Specific attention should be paid to organizations that reach youth to ensure their ongoing programs address PMTCT and responsible parenthood. 
Advocacy

PMTCT programs should advocate for broader prevention programs to address risky behavior, especially in youth and men, and to promote gender equality and sexual health for women and men. HIV program approaches to men should have the following three goals:

1. Promoting women's equal status in reproductive health decision-making in the context of gender equity.

2. Increasing men's support of women's sexual and reproductive health and of children's well-being, with equal regard for female and male children.

3. Meeting the reproductive and sexual health needs of men (in addition to those of women) (Adapted from Reproductive Health Outlook www.rho.org)

Using these goals as a guide, programs should be able to address legitimate concerns that targeting men may divert resources from badly-needed programs for women. Similarly, such an approach should allay a related concern that addressing men's reproductive health needs may worsen gender imbalance by strengthening men's traditional dominance in decision-making.

In addition to the male involvement activities implemented by the PMTCT program (described in Chapter I.D), PMTCT programs should advocate for an expansion and intensification of a comprehensive reproductive health program for men that includes the following HIV-related activities:

- Empowering men with skills to negotiate condom use within and without stable relations

- Family life education programs for boys

- Training health workers to focus on the special needs of men

- Offering services such as VCT, diagnosis and treatment of STIs other than HIV, and family planning at sites and times well-suited to male clients

- Providing high-quality, discreet STI/HIV services to men

To intensify HIV prevention services for youth, the PMTCT program should support actions to:

- Inform all children and young people about HIV/AIDS and provide them with opportunities to learn life skills to reduce their vulnerability and help them avoid risky behavior.

- Promote and expand young people's access to voluntary and confidential HIV testing and counseling, and to sexual and reproductive health services, including access to condoms and the treatment of sexually transmitted infections. 
- Promote awareness about HIV/AIDS and healthy lifestyles, help eliminate stigma and discrimination, and encourage communication between adults, children and young people.

- Reduce the vulnerability of adolescent girls, as well as children and young people at particularly high risk of HIV infection - street children, injecting drug users, sexually exploited children, children in prisons and institutions, and children and young people living in environments of violence and conflict.

- Ensure that young people are central to planning, implementing and monitoring these activities.

\section{II.B. Antenatal Care}

High quality antenatal care will not only improve the health of all mothers and increase acceptability of the PMTCT program, but may make a minor contribution to reducing vertical transmission rates. Reducing the incidence and severity of malaria, tuberculosis, and reproductive tract and other infections will improve the chances that an HIV-infected woman avoids or defers conditions that will compromise her health and survival. Better antenatal care will improve birth outcomes such as stillbirths, low birth weight, preterm births, and infant mortality, regardless of the HIV status of the mother. Furthermore, improving the nutrition of HIV-infected mothers may help to slow the progression of AIDS and prolong survival.

\section{Service integration and referral}

A comprehensive antenatal care package is the foundation of a PMTCT program. Programs should offer a full antenatal service which includes maternal tetanus toxoid immunization; STI screening and treatment; iron and folate supplementation; malaria treatment and tuberculosis treatment, where appropriate; and information on HIV prevention, VCT, infant feeding, and family planning. (The next section addresses appropriate obstetric practices.) Health workers should make each ANC contact an opportunity to address MTCT and provide information to clients. This type of service integration will ensure that both clients and health workers consider PMTCT an essential component of antenatal care. Moreover, by making PMTCT the responsibility of the entire staff, the burden for providing information will not lie solely on specialized PMTCT counselors.

\section{Linkages with other programs}

PMTCT sites should be fully stocked with micronutrients, reagents for syphilis testing and treatment, antimalarials, and other core supplies for all pregnant women. As PMTCT programs scale up, a vertical system of procurement and supply is not practical or sustainable, and thus PMTCT programs must work within a central system. Moreover, the PMTCT program should seek partnerships with food supplementation programs such 
as the World Food Program to provide adequate nutritional support for pregnant women and lactating mothers.

PMTCT programs should consult with partners and assess whether the recommended frequency of visits for antenatal care is appropriate or could be reduced. Although programs should continue to emphasize the importance of routine checkups, they can also adapt to the reality of irregular clinic attendance. Some programs, for instance in Zambia, have reduced the number of recommended ANC visits and now emphasize the importance of a few high-quality visits rather than a higher number of visits during which few services are provided.

\section{Advocacy}

Joining with colleagues promoting safe motherhood, PMTCT programs should promote universal access to antenatal care, including advocating free care or a waiver system for poor women. Use of ANC services is central to an effective PMTCT program and financial hardship should not deny women access. PMTCT programs should clearly articulate to international donors and national funders that it is appropriate and necessary to use PMTCT financial and technical resources to support comprehensive antenatal care, not just selected PMTCT interventions.

\section{II.C. Safe Labor and Delivery}

A substantial proportion of perinatal HIV transmission occurs during labor and delivery and immediately post-partum. This period should be the target of intensive PMTCT program efforts. Improving obstetrical practice entails working closely with safe motherhood programs to develop and disseminate appropriate guidelines which address HIV and MTCT, skills building, and ensuring that health workers have the supplies they need to safeguard their clients and themselves.

\section{Service integration and referral}

Improved obstetrical practice interventions to support PMTCT include reducing unnecessary instrumentation and invasive procedures, averting artificial rupture of membranes and prolonged labor, reducing unsafe medical practices, and improving home-based obstetric practices. A good discussion of these practices and suggested behavior change interventions to promote good practice can be found in Moore (2003).

\section{Linkages with other programs}

Complications of pregnancy are a major reason for blood transfusion the world over. The PMTCT program should link with programs that screen blood for HIV to ensure that all birthing sites have supplies of screened blood for pregnancy-related emergencies.

The PMTCT program must also work hand-in-hand with safe motherhood efforts to develop policies, guidelines, pre-service training, and programs which address reducing 
the risk of HIV infection in women and their infants. Another key area of collaboration is in training of traditional birth attendants. Such training should focus on appropriate obstetric practices which reduce the risk of MTCT during labor and delivery and lower the exposure of TBAs to infected body fluids. TBAs can also assist with:

- disseminating information about how HIV can be transmitted between mother and child and strategies to prevent such transmission;

- identifying pregnant women in their communities and facilitating their use of available antenatal and maternity care;

- reinforcing health messages, including the importance of improved nutrition during pregnancy;

- supervising directly observed treatment of mother and infant with nevirapine; and

- counseling on reducing the risk of HIV transmission to women and their partners.

\section{Advocacy}

Based on a review of the evidence in preventing maternal death, the Inter-Agency Group on Safe Motherhood identified skilled care during labor and delivery as a critical intervention to reduce maternal death and improve maternal and child health. The PMTCT program should support this recommendation and advocate - both to fellow program managers and clients - for all births to be assisted by a skilled attendant and to take place in a health facility, when feasible.

\section{II.D. Family planning}

Preventing unintended births among HIV-positive women is a highly effective strategy to reduce the number children infected with HIV. In addition, preventing such births contributes to the quality of life of HIV-positive women by relieving them of the burden and possible guilt of caring for infected children or of the prospect of creating additional orphans. Promoting dual protection - protection from both an unintended pregnancy and from disease — should be a key component of the PMTCT family planning strategy.

\section{Service integration and referral}

Programs should strive to eliminate missed opportunities to address client needs for both family planning and PMTCT. Many MCH clinics offer family planning services, sometimes using the same workers who provide PMTCT services. PMTCT group talks should include information on how women can avoid mother-to-child transmission of HIV by avoiding unintended births. During individual PMTCT contacts, staff should assess family planning preferences and discuss appropriate methods. HIV-positive women need specific information and counseling to help them think about sexuality and address their reproductive needs and rights. 


\section{Linkages with other programs}

Wherever women seek family planning services, health workers should give information about the risk of HIV from unprotected intercourse, offer HIV counseling and testing, and promote dual protection. Infant feeding counseling is another important chance to discuss family planning needs and methods. The PMTCT program should ensure that the counselors and mothers' groups who counsel and support women during their first few months of infant feeding address the risks of pregnancy associated with the different infant feeding choices. Such counseling should also help women avoid closely-spaced births that raise the health risk for themselves and their infants.

\section{Advocacy}

PMTCT programs should advocate and support their colleagues to incorporate HIV risk assessment and even counseling and testing within family planning services. The risk factors for HIV are well known, and a number of risk assessment checklists, tools and exercises have been developed for health workers to use during counseling - in individual or group sessions with peers, with and without partners, and for selfassessment. Family planning programs should try integrating these tools into their programs to help clients assess whether they may be infected or at high risk of infection and to make appropriate reproductive and contraceptive choices. Programs could also promote or offer voluntary HIV testing to women and men. An initial step may be to provide counseling about the advantages as well as the potential negative consequences of an HIV test and referrals for testing.

\section{II.E. Care and Support for HIV-positive Women, Partners, and their Children}

Once women learn that they are living with HIV they need support and empowerment to make and carry out a number of PMTCT-related decisions, including accepting the diagnosis of HIV infection, sharing their status with significant others, making plans, and coping with consequences of the infection as well as the reactions of their social network. Hence they need a continuum of comprehensive care. This continuum should start with the counselor who provides post-test counseling and supports the woman to accept her status and to share the HIV status with significant others. The counselor should also refer the woman for clinical care. Care for the HIV-positive woman and her family should also include helping her and her partner to access family planning counseling and services (discussed above).

\section{Service integration and referral}

The continuum of care should start during ANC. After the initial post-test counseling session at which the woman receives her HIV test results, further ongoing counseling should be scheduled to help her accept her HIV status and support her to disclose her infection to family and friends. Programs should integrate psychosocial support in all stages of care for the mother in the MCH clinic including the postnatal clinic as well as 
the child immunization clinics. Many programs have recruited peer counselors to assist with this type of support. A good example is the Kenya PMTCT project. In Homa Bay, the programs trains and employs peer counselors from among those HIV-positive women (identified from a local PLHA CBO) who have a supportive attitude and feel confident enough to support others. Clinic staff refer mothers to these peer counselors for further support. In addition, the PMTCT mothers have formed support groups that meet regularly and discuss issues such as income generation. Another example is the Mothers-tomothers-to-be program (M2M2B) initiated in Western Cape, South Africa.

Additionally, the ANC clinic should refer HIV-positive, pregnant women for medical care. In Homa Bay, PMTCT mothers are referred to a medical clinic within the same hospital where staff assesses their clinical needs and provides treatment for opportunistic infections as well as prophylaxis using cotrimoxazole and Isoniazid for tuberculosis. In addition some women have been put on HAART. The introduction of the MTCT Plus initiative as well as other programs offering HIV care will undoubtedly increase the number of referral sites for HIV-positive women diagnosed during antenatal care. HIV/AIDS care and counseling should also be integrated with the Integrated Management of Childhood Illness (IMCI) to enable health workers to address the medical and psychosocial needs of children of HIV-positive mothers.

\section{Linkages with other programs}

To help a woman appropriately disclose her HIV status to her male partner, the PMTCT program should link with services that will offer voluntary counseling and testing and-if HIV-positive - care and support services for men or the couple. This requires links with NGOs and CBOs that provide VCT and AIDS care and support. Similarly, the PMTCT program should link with other programs that care for children from AIDS-affected families.

In many countries, women and children with HIV are entitled to some welfare support or at least home-based care. PMTCT programs should link with organizations providing support to orphans and vulnerable children to meet the special needs of HIV/AIDSaffected children such as succession planning, and school fees. In Zambia, where lack of food is a major issue, the PMTCT program provides food support to mothers via other programs that are providing food for tuberculosis patients (McCoy et al. 2002). In South Africa, PMTCT staff in one state network with welfare providers to help alleviate poverty. In addition to the usual tasks of psychosocial support, PMTCT counselors also help clients gain access to community support groups and welfare grants (Rapid Assessment Findings). In countries such as Zimbabwe with an AIDS levy fund geared towards support of PLHAs, PMTCT counselors should link with PLHA groups and help mothers draw on such funds.

\section{Advocacy}

While existing policies promote a range of PMTCT care and support strategies, efforts are inconsistent, and the current standard of care in public health services omits many 
recommended strategies. In general, HIV care and support services are still limited to a few NGO-managed sites either within hospitals or in community-based settings.

Advocacy is needed to encourage policy makers and donors to increase the level of resources and ensure that countries consistently and broadly provide HIV care and support using integrated, sustainable approaches. For example, advocacy efforts should build on the MTCT Plus project to help prioritize PMTCT women and their families for HAART — currently not widely available in public institutions in developing countries. PMTCT mothers are an optimal group for HAART because they will have received counseling about ARVs and may have higher adherence rates to HAART. Also, prolonging the lives of PMTCT parents using HAART helps to delay the orphanhood of children who PMTCT has saved. Moreover, the expansion of care to the mother is likely to encourage more women to seek or accept HIV testing during ANC.

Programs also should advocate reducing stigma towards HIV-positive people and especially towards mothers who are not breastfeeding. Programs should try different strategies that inform the community about breastfeeding and HIV but do not stigmatize non-breastfeeding women. One program that combats general HIV stigma is the Chinkankata project in Zambia (Campbell and Rader 1995). The project supports the HIV-positive individual to share their status confidentially in a way that integrates individual rights with public responsibility. Community counsellors allude to the presence of people with AIDS but do not point out specific infected people. This information is kept in "shared confidentiality" in which people know but do not discuss directly. Instead, meanings and implications are acknowledged and explored. Secrets can become open at the pace and initiative of the community group. Individuals can selectively release information of a sensitive, personal, and confidential nature. 


\section{Systems for PMTCT}

\section{III.A. Community Engagement and Advocacy Strategy and Implementation}

A communication framework provides a strong foundation to address key PMTCTrelated issues such as primary prevention; uptake of PMTCT interventions such as VCT, ARVs, and recommended infant feeding practices; involvement of men, youth and PLHAs; community-based care and support; and stigma and discrimination. The essential components of a PMTCT communication strategy and its implementation are behavior change communication, community engagement, social mobilization and advocacy. An integrated communication strategy should provide solutions that are realistic, feasible and based on input and guidance from community and civil society members.

\section{Q. We are just starting up a PMTCT program. What priority should I give for communication activities?}

A. At the pilot stage, it may be necessary to prioritize getting services up and running. If premature, communication activities will raise expectations and then disappoint communities who find that services are not yet in place. However, it is very important that communication efforts do not lag far behind the initiation of services. The lack of extensive communication activities has hindered the uptake of services in many countries. For instance, many women hear about VCT for PMTCT for the first time only upon entering the clinic. As such, they are not necessarily ready to confront the possibility of HIV in their lives. Your program should develop services and communication components in tandem, so that service readiness is complemented by community preparedness. It is equally important that communication activities are not one-off, but that they continue at regular intervals.

\section{Q. What should be the main message as to why women should participate in PMTCT programs?}

A. The central message of communication activities should be: give your baby the chance to be healthy and HIV-free. At the same time, programs must communicate clearly that PMTCT interventions are not 100 percent effective. It is important to explain the efficacy rate of ARVs so that women do not feel that they were misinformed. It is also important to recognize that your program may be criticized because it does not offer ongoing ARVs treatment for HIV-positive mothers. Hence, an important secondary message is that women will benefit in a variety of other ways by participating in PMTCT programs.

\section{Q. Should we direct communication activities to men?}

A. It is essential to tailor communication activities specifically for men of reproductive age. Understand men's perspectives and their vested interests before developing messages. A comprehensive communication strategy should address what men need to 
know and the factors that might motivate them to support the participation of their partners in PMTCT programs. In most countries, the lack of male support blocks many women from getting some of the essential PMTCT services, especially HIV testing, completing the ARV regimen, and feeding an infant contrary to community norms. PMTCT need men as allies and active supporters.

\section{Q. What are some typical communication activities of PMTCT programs?}

A. The following are common examples:

- brochures / pamphlets

- posters

- pre-counseling informational videos

- drama groups

- radio messages

- newsletters

Q. What are key principles for an effective communication strategy and its implementation?

A. The following are key principles:

- Base the strategy on existing policies and guidelines

- Make messages consistent across all sectors and agencies

- Ensure inclusion of men and families

- Seek cost-effective communication methods

- Consider all four prongs of PMTCT

Q. What are the objectives of a communication strategy and its implementation?

A. The following are common objectives:

- To develop leadership commitment at all levels

- To create alliances of partners for changes in social norms

- To increase participation and leadership/ownership at community level

- To support appropriate behavior change

- To increase demand for PMTCT program and components

\section{Q. How do I create a communication strategy?}

A. Rather than developing top-down communication materials and activities, get input from communities and target audiences. Various countries have successfully used the 
ACADA process (Assessment, Communication Analysis, Design, and Action) for qualitative, audience based research. Moreover, the perspectives and experiences of PLHAs add to the richness of a communication strategy, for instance in addressing stigma. Community-level catalysts or facilitators are important mediators between the health system and the community. Programs should identify and build the capacity of these individuals or organizations (e.g. community leaders, community-based organizations, neighborhood health committees, etc.) as a way to make community engagement in the PMTCT program a reality. In this regard, local teams should work with pilot communities to identify such catalysts. Mechanisms for documenting and sharing lessons learnt across pilot sites and across districts can accelerate diffusion of communication innovations.

\section{Q. What should a communication strategy emphasize during scale up?}

A. Most PMTCT communication strategies for scale up will focus on:

- Advocacy for leadership commitment to scale up PMTCT and to support policies on infant and young child feeding;

- Social mobilization for catalyzing civil society and opinion leaders to endorse social norms for men's involvement in PMTCT, ensure appropriate infant feeding choices, and to create a caring community for AIDS-affected mothers, children, and families;

- Community engagement with the aim of building local capacity to respond and cope, to claim rights and responsibilities, and to ensure the sociocultural relevance of programs;

- Interpersonal communication skills for counseling and continuation of successful behavior change approaches such as peer education.

The need is also clear to decentralize communication strategies to foster ownership at the district and local level and to enhance implementation. Media partnerships can amplify successful local and district initiatives. 


\title{
III.B. Coordination
}

The complex and multisectoral nature of PMTCT programs requires strong leadership and good coordination for the success of both pilot and scaled-up programs. Carrying out PMTCT means drawing on many types of institutions and individuals including government, technical resource experts, NGOS, people living with HIV/AIDS, community representatives, and the media. Moreover, as international donors increase their support for PMTCT, the need for mechanisms to coordinate funding will rise.

\section{Q. What should be the purpose, membership, and responsibilities of a central PMTCT coordinating body?}

\begin{abstract}
A. All countries with pilot projects have established central coordinating bodies, underscoring their importance. Prior to scaling up, informal or semiformal structures should become formalized, to acquire the authority and resources needed to coordinate PMTCT activities. A multisectoral membership should include government officials, technical resource people, donors, nongovernmental and community-based organizations, people living with HIV/AIDS, and other groups. The coordinating body may report to line ministries and to the national AIDS council. Key responsibilities of this group include:
\end{abstract}

- strategic planning

- guideline development

- program monitoring

- quality control

- information sharing with all stakeholders

- linkages with other programs

- identification of research priorities

- articulation of technical issues

- articulation of policy issues

- advocacy

- resource/donor mobilization and coordination

- streamlining PMTCT response, regulation, and approval

- development of a scaling-up plan including budgeting.

An alternative approach is to create two coordinating bodies, one with a policy-making role and a second to address technical issues. Regardless of the number of committees, the national program should have a full-time manager who is part of the coordinating group(s), with day-to-day responsibility for the PMTCT program.

\section{Q. What are strategies to coordinate the many different implementing agencies?}

A. Many countries have experienced an influx of donor and implementing agencies wanting to contribute or already contributing to PMTCT activities. Partnerships are 
essential because most governments lack the resources to start or scale up PMTCT services. Governments should allocate carefully roles and responsibilities among partner organizations, ideally matching these roles with identified strengths. The central coordinating body should approve any program efforts as a way to prevent duplication and to encourage the development of a single, national PMTCT program.

\section{Q. What are the respective roles of government and donors/partners?}

A.

Government roles:

- Policy

- Planning

- Development of standards/guidelines

- Resource allocation

Donor/Partner roles:

- Support national response

- Advocacy

- Identify and fill gaps (such as personnel at local and national levels) and strengthen weaknesses

- Build or support national capacity

\section{Q. What role can NGOs play in government programs?}

A. NGOs may take on a variety of roles. For instance, the government may choose to subcontract NGOs for training and counseling. Such arrangements must, however, handle compensation issues with care. If NGOs employees make significantly more than their government-paid colleagues, serious morale problems could result. NGOs also are potentially important providers of care and support services, which the typical ANC clinic has difficulty implementing on its own. The government can involve NGOs either through referral or via a more formal subcontract. For administrative simplicity, governments may prefer to subcontract for services at multiple sites rather than clinic by clinic.

\section{Q. How does the role of the central coordinating body change as a program expands?}

A. One key task is to develop a comprehensive national program implementation framework. The framework should include:

- a description of the PMTCT minimum package;

- a plan for phased expansion according to agreed-upon criteria; 
- a human resource and supply plan which forecasts program requirements and costs;

- an institutional framework clarifying roles and responsibilities;

- a comprehensive communication strategy; and

- a monitoring and evaluation plan.

Both donors and program managers can then buy into this plan, applying their resources to the technical or geographic areas in which they have comparative advantage. The central coordinating board should monitor all partners to ensure that their activities are consistent with the national framework, that they are providing all major program inputs, and that their efforts are broadening coverage and minimizing duplication.

Before countries scale up, they will need to establish and strengthen decentralized coordinating teams, ${ }^{6}$ one type for policy making and another type of team to play a technical role.

Table 6 Suggested Roles for Coordinating Teams

\begin{tabular}{|c|c|}
\hline Role of policy-making body & $\begin{array}{l}\text { Role of technical body (Multisectoral } \\
\text { including NGOs, CBOs, and PLHA) }\end{array}$ \\
\hline $\begin{array}{l}\text { - Policy decisions } \\
\text { - Resource/donor mobilization and } \\
\text { coordination } \\
\text { - Advocacy } \\
\text { - Identifying research priorities }\end{array}$ & $\begin{array}{l}\text { - Strategic planning } \\
\text { - } \text { Guideline development } \\
\text { - } \text { Program monitoring } \\
\text { - Information sharing with all } \\
\text { - stakeholders } \\
\text { - Advisory to the policy group } \\
\text { - } \\
\text { - Identablish linkages with other programs } \\
\text { - Advocacy }\end{array}$ \\
\hline
\end{tabular}

Source: UNICEF 2002.

\footnotetext{
${ }^{6}$ An important lesson of attempts at large-scale multisectoral planning for nutrition and integrated rural development in the 1970s and 1980s was that it is impossible to scale up multisector programs by relying upon central agencies for implementation. These central planning agencies have been superseded by decentralized and participatory mechanisms for planning and implementation.
} 


\section{III.C. Human Resources and Capacity Development}

As with any new health service, introduction of PMTCT requires training health workers to acquire specific knowledge, skills, and attitudes. At the same time, institutions must create an enabling and supportive environment that motivates workers to effectively apply their learning. Although challenges still remain, PMTCT programs have made large strides in training PMTCT providers. Training has increased the number of knowledgeable and capable staff and has had important positive effects on the attitudes of health workers and on reducing stigma toward women infected with HIV.

Nonetheless, service delivery points are still short on staff with the skills to provide HIVrelated care, particularly trained counselors. High rates of staff turnover and lack of training for nonclinical staff continue to hamper program effectiveness. The introduction of services to prevent mother-to-child transmission of HIV has had a mixed impact on motivating health workers in the maternal-and-child health setting. Although many workers are encouraged by finally getting the tools to help clients and their babies fight HIV/AIDS, the extra work can be a disincentive for underpaid, under-equipped staff, whose own HIV-related needs are rarely met.

Building health worker capacity through training will only be effective if programs equally stress giving trained workers the means to carry out interventions. That means coupling increased technical knowledge with improved motivation and supervision and with functioning systems.

\section{Q. Besides the one-off PMTCT training, what are other training needs?}

A. After health care workers undergo PMTCT training, it is equally important that supportive supervision reinforces the training on site. That requires supervisors thoroughly trained in PMTCT interventions. Other training needs include:

- Refresher or follow-up training for specific components of PMTCT such as infant feeding counseling. Programs should update workers as technical guidance evolves and address knowledge gaps identified in supervisory visits.

- Lab training to carry out HIV testing. This training may be undertaken by lab technicians as well as by counselors.

- Training traditional birth attendants to give HIV-positive women appropriate support, for example, in carrying out modified labor practices and helping ensure that women take their ARVs. The program in Zambia has taken this approach.

- Training of community or lay counselors, as has happened in Botswana, Malawi, South Africa, and Zimbabwe.

- Training for standardized data collection as a way to monitor and evaluate programs for effectiveness and possible gaps.

\section{Q. Should training be centralized or decentralized?}


A. Countries that are starting PMTCT services can choose either option. Centralized training may be easier because only a small group will likely be working on and knowledgeable about PMTCT. However, decentralized training for pilot programs makes it easier to provide critically-needed on-site supervision. During pilot programs, managers should ensure that decentralized training has consistent content and duration.

Countries that are taking the program to scale should decentralize their training to ensure a steady pace of expansion and maintain a cost-effective approach. The aim should be to build a decentralized pool of trainers and training facilities that can carry out training without minimal involvement from central authorities. Nonetheless, maintaining the quality of decentralized training remains a big problem. Programs may want to contract an NGO or other private institution to hire and manage trainers. Botswana, Uganda, and Western Cape Province in South Africa have taken this approach.

\section{Q. What human resource planning should PMTCT programs do to prepare for scale up?}

A. Human resource planning for scale up should include:

- estimating current and future demand for the program's services keeping pace with strengthened community engagement efforts;

- establishing types of services provided and activities carried in facilities and communities, for example if the program includes an outreach component or provides community-based care and support;

- estimating which types of health care workers will carry out these services as well as the skills needed to do so; and

- projecting associated costs.

To make such planning possible, decentralized management teams may need to undergo capacity building.

Q. What priority should we give to enhancing pre-service medical curricula and how do we go about it?

A. Adding PMTCT into the pre-service curriculum is an important medium-term goal that programs should pursue alongside scaling up. Ultimately it would reduce the amount of in-service training needed for PMTCT. One method for introducing PMTCT into the curriculum is to ensure that PMTCT questions are part of final examinations. When one medical school in Uganda used this approach it obliged lecturers to cover the topic.

\section{Q. Several staff members who recently received training in PMTCT now have left. How should we address this problem?}

A: Programs using centralized training should have the flexibility to train quickly new staff at sites with high turnover. Rather than initiating new PMTCT sites, the program 
should provide further support at these existing sites that have supplies and other components of PMTCT services already in place. Under a decentralized approach, the trained supervisor may train new staff members on site, perhaps with help from another trainer.

Q. Staff in many PMTCT programs suffer from low pay, heavy workloads, and low motivation. What are some ways of better motivating or rewarding PMTCT staff?

A.

- Programs could reward health workers who are performing well by selecting them to undergo PMTCT training. This is most likely to be effective where training carries high value and prestige.

- Programs should take opportunities to recognize and praise dedicated health workers.

- Managers should emphasize that PMTCT fills an important health gap. The feeling that they are providing a needed service to the community helps raise the motivation of health care workers.

- Programs can establish partnerships or more formal contracts with NGOs to hire government health workers on weekends or during other free time to pay them for additional work.

- Programs can, via NGOs, hire additional health workers to lessen the workload. In such cases, pay equity must be a top priority.

- Officials must also advocate for increased health budgets to allow for more, better-compensated health workers.

Q. Staff shortages have forced us to recruit lay counselors. Unfortunately, the professional counseling and nursing staff has not reacted positively. How do we address these attitudes?

A. It is understandable that professional staff may not welcome lay counselors into the clinic. For that reason it is important to emphasize that lay counselors are there to help relieve the heavy burden on the professionals and allow all staff to meet client needs more fully. Clinic managers will have to outline clearly roles so that professional staff do not feel threatened, but rather see themselves as supervisors, trainers, and mentors of the lay counselors. Moreover, for professional staff who are interested in working extra hours for PMTCT, they should be given these opportunities to do so.

\section{Q. Many of our counselors get burned out under the stress of repeatedly telling women they are HIV-positive. How can we address this problem?}

A. Regular debriefing sessions are one opportunity for counselors to share experiences and coping strategies. Simply hearing that other counselors are having some of the same difficulties provides support. Debriefings are also an opportunity to share the positive experiences that motivate workers, most of all the sense that counselors are helping women and their families. A more experienced counselor could facilitate the session and 
help counselors address difficult scenarios. Such debriefings should at all times maintain client confidentiality. 


\section{III.D. Laboratory Support}

Q. We already have a laboratory that is providing HIV testing for sentinel surveillance of ANC women. Now that we want to start PMTCT services, do we need to make any changes?

A. Yes. There are a number of differences between HIV testing for sentinel surveillance and HIV testing for PMTCT. First, the tests you are using are most likely to be ELISAbased, which may take up to a week before giving results. A week is too long for some mothers to wait and others may not return for the results. For PMTCT, you should use rapid tests that give HIV results on the same day. If you make this choice, you will need to train your laboratory staff on the new rapid tests. Second, testing for sentinel surveillance does not link a name to a test result and you do not send the results to any provider to give the patient. With PMTCT you will need a new record system in the lab that allows you to return results to the counselor who will in turn notify the mother during post-test counseling.

Q. We already test for HIV in the general population VCT program run from the outpatient department. What changes do we need to make to provide HIV testing for PMTCT?

A. Laboratory and administrative procedures for HIV testing for VCT in the general outpatient department are almost the same as those for PMTCT testing. However, you may need to adjust for the large numbers of ANC women who come in the morning and thus pressure the lab to test many samples in a short time. Some labs have responded by dedicating specific staff to PMTCT testing while others have set up a side lab in the ANC to focus on PMTCT testing. In some sites the laboratory technicians have successfully trained the ANC midwives to carry out rapid HIV testing while continuing to provide oversight.

\section{Q. Does the lab need any special quality assurance for PMTCT-related HIV testing?}

A. No. If the hospital lab already has a quality assurance arrangement with a body such as a national health research laboratory, you should continue the arrangement. Usually quality assurance agreements require that the hospital lab send about 5 percent of HIVnegative samples and all HIV-positive samples for quality assurance.

Q. We have not been doing any HIV testing in this hospital. What do we need to put in place to provide HIV testing for the PMTCT program?

A. First the National Health Research Laboratory and the PMTCT program manager need to agree on the types of test kits and systems for their procurement, supply, and storage. They also need agreement on the test site (whether in the main lab or in a side lab within the ANC clinic) and who is going to do the test (the lab technicians or the midwives in 


\begin{abstract}
ANC). Once they agree, they should assess the human resources, space, supplies, and equipment available in the laboratory. Following the assessment, they should conduct appropriate training, procure equipment and supplies, and put in place record systems.

\section{Q. Can we test for HIV when a mother is in labor? If so, what preparations should the laboratory make for such emergency testing?}

A. You can test women in labor. The ideal arrangement would be a side lab by the labor ward. Alternatively, you could train midwives in the labor ward to do rapid tests. A third option is to train staff in the hospital lab that handles emergency blood transfusion to carry out rapid HIV testing and instantly send results to the labor ward. 


\section{III.E. Management}

\section{Q. What is the role of managers during scale up?}

A. Managers at subnational, district, and site levels are vital to the effective scaling up of PMTCT activities. Before and during scale up, consultation and sensitization meetings, training, and other activities should take place to obtain their input and buy in. Without managerial support, it is very difficult for health care workers to put in practice their new skills. Programs need to both empower and train midlevel managers to address adequately operational issues that will inevitably arise. Their ability to solve problems and to galvanize staff contributes to a successful effort. Thus, programs must boost the morale of and encourage leadership among managers at all levels.

\section{Q. What are some critical management challenges in scaling up PMTCT programs?}

A. The big challenge is to move towards decentralized and participatory planning, management, and implementation. Because it is likely that only a few people at the center managed the pilot program, the decentralization process may not come easily. The program needs to outline clearly the roles and linkages between national and district stakeholders and establish regular monitoring meetings with participation of all partners at the national and district levels to identify and resolve service problems. Timely and appropriate human resource recruitment and deployment is a key component of effective decentralization as well. 


\section{III.F. Monitoring and Evaluation}

\section{Q. What are the essential elements of my monitoring and evaluation ( $M$ and $E$ ) system?}

A. You need to collect the data which are critical for decision-making while keeping the $\mathrm{M}$ and $\mathrm{E}$ system lean. The main objectives of your $\mathrm{M}$ and $\mathrm{E}$ system are to collect data for monitoring the coverage, acceptability, and quality of your program, measuring whether your program inputs are achieving your program objectives, and advocating for continued support and expansion. As you design your $\mathrm{M}$ and $\mathrm{E}$ system, remember to:

- Sort indicators into those you collect from service delivery sites and others you collect at the country level (for instance, knowledge of MTCT). For the latter, rely on non-program data sources such as the Demographic and Health Surveys (DHS).

- Expand your vision of indicators beyond services components, for example, to include stigma, prevention, and critical incidents.

- Integrate PMTCT M and E with existing systems and registers.

- Link supply monitoring with program monitoring.

- Train clinic staff and managers in M and E.

- Aim high, but be realistic. Patient-centered information which captures how many women went through the whole program is the gold standard and particularly important for measuring program impact and how the interventions have benefited children. Such evaluation is, however, challenging and probably not feasible or appropriate except in selected research settings.

\section{Q. What should my PMTCT program measure?}

A. At a minimum your $\mathrm{M}$ and $\mathrm{E}$ system should include measurement of:

- Program inputs

a. Number of trained staff deployed to PMTCT programs

b. Multisectoral IEC community engagement strategy developed and being implemented at site, subnational and/or national level

c. Support communication materials (for PMTCT, ANC, VCT) on site in quantities sufficient for distribution

d. Job aids addressing PMTCT counseling/talking points available on site

e. Numbers and types of $\mathrm{NGO}, \mathrm{CBO}$ and other partnerships engaged in activities that support PMTCT

f. Supplies (from supply information system)

- Service statistics on program activities and utilization

a. Number of first ANC visits 
b. Pretest counseled (depending on structure of VCT)

c. Tested

d. Posttest counseled / Reviewed results, numbers referred knowing their status

e. ARVs (all regimens) administered

f. cotrimoxazole and referrals to care and support

g. Deliveries at facility and those who report to facility immediately after birth

h. Infant feeding choice at birth and practice at 6 months

i. Reported consistent contraceptive/condom use at 6 months

j. Eliza measurement of infant HIV status at 18 months

Additionally, special studies of the following topics are needed to ensure that all PMTCT program components are being adequately addressed:

- Use of family planning among HIV-positive women

- Adherence to ARVs

- Impact of participation in PMTCT on HIV knowledge and protective behavior

- Male involvement

- Infant feeding

- Quality of care, with special attention to counseling, based on observations of services and exit interviews

- Reasons for non-use of PMTCT services

- Secondary analysis of DHS and other national surveys to track PMTCT knowledge and participation on a national scale

Q. Our health workers are already inundated with registers and forms. How can I minimize the burden of PMTCT-related data collection?

A. ANC visits and births are already part of routine ANC statistics while infant feeding practices are part of the growth monitoring system. Because PMTCT is part of routine ANC, you should add tracking the voluntary counseling and testing services to routine ANC statistics. Because ARVs and cotrimoxazole are provided only to HIV-positive women, tracking the issuance of these drugs will require a special register of services provided to HIV-positive women.

\section{Q. How do I use the information I collect?}

A. Produce simple reports and highlight strengths and weaknesses in service delivery as well as difference between sites or districts. Share these reports with sites or districts as both a management and motivational tool. Build on existing mechanisms to share information such as forums where district managers meet to discuss issues and analyze data. 
Q. What kind of structure, staff, and expertise do I need to do effective monitoring and evaluation?

\begin{abstract}
A. Clinic staff should collect routine data and each $\mathrm{ANC} / \mathrm{MCH}$ team leader or site manager should compile weekly reports to forward to the district level. District officials should then enter the weekly report for all sites into a computerized database and submit a report to the national level. Ideally NGOs and for-profit medical professionals would also contribute to and participate in the district and national data bases.

Staff requirements include the time of a data entry clerk in each district, a database manager at the national level, and an evaluation and research manager to prepare and disseminate service statistics reports and oversee special studies. The program can commission special studies to a university or other researchers or ask students to carry them out as part of their training in public health or medicine.
\end{abstract}

\title{
Q. What changes do I need to make in the monitoring and evaluation system as the PMTCT program goes to scale?
}

A. Scaled-up programs require simpler systems of $\mathrm{M}$ and E. First, information needs are changing from a focus on learning how to design a program to one of program monitoring. Second, a larger program means that to maintain ease and accuracy of data collection you will have to focus on less data and fewer indicators. 


\section{III.G. Physical Structure}

\section{Q. Do PMTCT programs require new or additional space?}

A. Because they are integrated into $\mathrm{ANC} / \mathrm{MCH}$ settings, PMTCT programs normally do not require new or additional space. Programs have been successfully installed in hospitals, health centers, and health posts - many with high client volumes. Health workers have been creative in their use of existing space for PMTCT services, such as using waiting rooms, large hallways, or outside patios for health education talks.

Q. Does the introduction of a PMTCT program require any change in the organization of the physical space of the ANC clinic?

A. Clinics should have a dedicated space to allow privacy for counseling. The private space will ideally be large enough to accommodate one-on-one and couples counseling, as well as small group pre-test counseling.

Q. We currently have two counseling rooms. One doubles as a supply room, causing frequent interruptions. How do I address this problem?

A. It would be best to try to store supplies elsewhere. If that is not possible, set up a schedule so that staff will know when not to interrupt counseling sessions. You may also want to post a sign that indicates when sessions are taking place.

Q: Our small clinic would like to offer PMTCT services but we lack counseling rooms. We have enough land surrounding the clinic, but not enough indoor space. How do I address this problem?

A. As a short- to medium-term solution, you could hold counseling sessions outside assuming good weather and the possibility of creating privacy through the natural landscape. For instance, you might select a tree that is a bit further away from where women queue for services, to facilitate private conversations. As a long-term solution, you may want to ask a business or community group to donate funds to build space or build it themselves. Furthermore, you might make arrangements whereby these organizations use the space when the clinic is closed.

Q. We are already offering PMTCT counseling although there is no private space. The counseling room only has one entrance, but is used for two separate counseling sessions due to serious space constraints.

A. Perhaps you can alter the room by creating a wall as a divider between the two areas. If that is not feasible or desirable, install temporary dividers so that clients are not able to see one another during sessions. Also, counselors can speak in low voices to reduce the extent to which conversations are overheard. 


\section{III.H. Policy Review or Development}

Q: What resources exist to help officials developing policies to support MTCT?

A: Several countries have already written PMTCT-related policies. Review these existing policy documents before starting from scratch..

\section{Q. What are some policy review or development issues for VCT?}

A.

Opting out. Policies should clearly support the "opt out" model of VCT. Under this approach, health workers present the HIV test as routine for all pregnant women, but still give clients the opportunity to decline taking the test.

Age of consent. Many countries currently prevent young people from accessing medical procedures without the consent of parents or guardians. Policy should allow minors access to VCT without this consent (Boswell and Baggaley 2002).

Testing by non-laboratory personnel. Since rapid testing is recommended, it is important that policy allows non-laboratory personnel to conduct HIV tests. 


\section{III.I. Supervision}

Q. PMTCT administratively belongs to the HIV/AIDS program but it is the reproductive health staff in the hospital actually providing the services. Who should the PMTCT staff report to?

A. The ministry of health's coordination body for PMTCT should include both the AIDS control program and the reproductive health unit. The manager of the national PMTCT program supervises PMTCT and informs the relevant administrative units of the ministry through the coordination body.

Q. In the teaching hospital, the PMTCT program is operated by pediatricians but most activities take place in the antenatal clinic and the labor ward, which are under the Ob-gyn department. What are the proper lines of supervision and reporting?

A. Clearly, there should be coordination between the pediatricians and the ob-gyns. The issue of PMTCT concerns both departments. For reporting, staff working on PMTCT in the ANC clinic and labor ward should continue to report to the ob-gyn managers and those working on PMTCT in the pediatric wards should likewise report to pediatrics. PMTCT services should be fully integrated into the routine services of both ob-gyn and pediatrics.

Q. I am a midwife working in ANC. I have been trained as a counselor by the head of the VCT unit in the outpatient department. I am a VCT counselor for the PMTCT program. The nursing sister who heads ANC has not been trained in HIV counseling. Who supervises my VCT activities for the PMTCT program?

A. Here you have two types of supervision to consider. For counseling supervision and support the counselor in the VCT unit in an outpatient department is a better supervisor. For administrative supervision, you should report to the sister-in-charge of ANC. Even if she has not been trained in counseling she has to know how many clients you are counseling as well as key outcomes such as the number accepting to be tested and the number receiving results.

Q. We have been told to collaborate with TBAs and refer to them mothers participating in the PMTCT program who choose to deliver at home. How shall we supervise the work of the TBAs?

A. In some countries, health staff have developed a supervisory relationship with TBAs after training them in PMTCT. Mothers wanting to deliver with a TBA are given the name of a nearby trained TBA, who helps ensure that both mother and baby take their intrapartum dose of ARVs. The TBA then brings the mother to the hospital for the one week postnatal check-up and reports the birth. This system works well because it elevates 
the status of the TBA and makes them part of the system. It also helps the health system to better monitor use of ARVs.

\section{Q. What kind of supervisory tools should we develop for PMTCT?}

A. Supervisors need checklists that help them to monitor how well VCT counseling, ARV discussion and infant feeding counseling are carried out. the national PMTCT program will have to develop and field test these tools to ensure uniformity and comparability of data from different sites. 


\section{III.J. Supplies}

Q. What steps should be taken to address supply issues for PMTCT programs?

\section{A. The following five steps should be taken:}

Step one: Ensure that supply management is appropriately coordinated

Step two: Ensure that PMTCT equipment and consumable commodities of appropriate quality are selected following recognized criteria for inclusion in procurement lists

Step three: Ensure that PMTCT equipment and consumables are procured through reliable and cost-effective mechanisms

Step four: Ensure appropriate storage and reliable cost-effective distribution of PMTCT equipment and consumable commodities

Step five: Ensure appropriate use of PMTCT commodities not only to streamline supply chains but also to ensure appropriate patient care in ANC settings

Q. What are the roles and responsibilities of the national government in ensuring appropriate PMTCT supplies?

A.

- Review legislation to ensure affordability of essential commodities that are under patent

- Set up mechanisms to coordinate supply availability with decentralization strategies and avoid vertical programs

- Perform rapid assessment of districts

- Develop integrated supply strategy linked to implementation strategies

- Allocate resources

- Develop timelines

- Define roles and responsibilities of partners

- Develop information systems that will support program management and provide information for monitoring and evaluation

Q. What are the roles and responsibilities of international donors in ensuring appropriate PMTCT supplies?

A.

- Advocacy to support PMTCT and PMTCT Plus and for changing legislation to allow affordability

- Providing information on:

- Basic commodities (specification) 
○ Sources of supplies

○ Quality standards

- Prequalified suppliers

- Reference prices

- Providing technical support on supply management at the regional, national, and district levels

- Supporting training and building capacity

- Mobilizing resources

Q. PMTCT pilot programs have begun with donations of AZT and nevirapine from pharmaceutical companies. Should we continue to advocate for donations?

A. Recent developments in the pharmaceutical sector have reduced the prices of ARV's substantially. However, even at reduced prices the branded products are often too expensive for most poor countries. Quality generic drugs are available on the international markets. To ensure access to more affordable drugs, governments need to review the patent status of drugs and, where necessary, adapt legislation to allow the procurement of such products through international competitive bidding procedures.

\section{Q. Should PMTCT supplies be procured separately or as part of the regular supply chain?}

A: For scaling up access to PMTCT services, there are no alternatives to using the existing ANC/MCH procurement and supply systems for PMTCT supplies. If this chain is weak, the PMTCT program will be vulnerable to the same supply problems that beleaguer many $\mathrm{MCH}$ programs and strengthening this supply chain should be a priority activity. 


\section{Scaling Up}

\section{IV.A. Introduction}

\section{Q. What do we mean by scaling up of PMTCT programs?}

A. In the context of this document, scaling up means taking a program operating in pilot sites and expanding it to reach more people in more sites within a region or country. The ultimate goal of scaling up is to ensure that the largest possible number of clients have access to high-quality, effective PMTCT interventions. Although many health programs tend naturally to expand over time, scaling up implies deliberate and planned growth.

Going to scale requires that managers perform specific tasks to ensure that expansion occurs and that the scale-up process does not reduce the effectiveness of PMTCT efforts. These tasks are outlined at various places throughout this document:

- Chapter 1 addresses scale-up issues specific to the component being discussed.

- Chapter 3 addresses scale-up issues as they relate to individual PMTCT systems (policy, human resources, etc.)

- This chapter focuses on two key cross-cutting elements of scale up: site selection, and financing and sustainability.

\section{Q. What is different about going to scale with PMTCT?}

A. In broad terms, scaling up PMTCT is similar to scaling up other health and development programs. However, the nature of PMTCT intensifies some of the scale-up challenges. Like other HIV/AIDS programs, PMTCT is caught in the debate over how best to beat the epidemic. This can hamper efforts to secure the financial and policy backing needed to go to scale. Moreover, the relatively large numbers of interventions that make up the PMTCT package require an extraordinary level of coordination; adding the links to HIV prevention and care and support elevates this complexity. To a greater degree than most programs, the technical guidelines for PMTCT are evolving rapidly, for example with respect to infant feeding and ARV prophylaxis. Finally, although like many interventions PMTCT relies heavily on trained and motivated health workers, the additional responsibilities - in particular the introduction of VCT - places a unique and emotionally exhausting strain on health workers. To rise to the challenges of PMTCT scale up is not without potential reward, however. PMTCT offers a unique entry point for strengthening prevention, care and support, as well as other critical cross-cutting services and systems that have long been viewed as crucial in the fight against HIV/AIDS.

\section{Q. What are effective models for scaling up PMTCT?}

A. No single model is effective in all countries. Some programs are concentrating on scaling up in districts where a pilot site exists while others aim to put at least one site in every district. Although the initial focus has been on the public sector, scaling-up 
strategies should also incorporate private for-profit and NGO health care workers, particularly in countries with weak public health systems.

\section{IV.B. Site Selection}

\section{Q. How do I choose pilot sites?}

A. Start with a small number of pilot sites, so that management and other start-up challenges do not overwhelm the program. The ideal number of pilot site will vary depending on the size of the country and stage of the epidemic, but should not exceed six. Because PMTCT piggybacks on existing facilities and services, it is important to choose pilot sites that already provide the range of basic $\mathrm{ANC}$ and $\mathrm{MCH}$ services and that have a relatively strong and effective management and quality of care. In addition, select pilot sites in areas with relatively high rates of HIV/AIDS infection. Doing so ensures that services go first to the most-affected regions and gives managers and health workers the best chance to quickly test and adjust new procedures and systems. It is also useful to choose pilots that embrace a range of contexts, including for example, a large urban clinic, small district hospital, rural clinic, government facility, mission facility, etc. Also, choose pilot sites with available laboratory support.

Case Example: In Rwanda, each pilot site was chosen on the basis of HIV prevalence, and according to the availability of ANC, maternity, laboratory, and nutrition services, as well as strong center management. The Ministry of Health also determined that each province have at least one site.

\section{Q. How do I select sites for replication of the PMTCT program?}

A. You should take into account a variety of important criteria when choosing sites for replication. It is vital to set up the program first in areas of HIV prevalence. Once you have chosen priority regions for replication, identify the specific sites for replication. Sites eligible for replication should, at a minimum, have functioning, basic ANC/MCH services. In addition, sites should have capacity for VCT and commitment from local authorities. Below are examples of criteria used in Zambia and Uganda to select sites for scale up.

Case Example: In Zambia, A PMTCT expansion subcommittee provides technical support to the expansion phase. The subcommittee has identified potential new sites according to the following criteria laid down in the Zambia National HIV/AIDS STD and TB Institutional Framework, 2001-2003:

- high HIV/AIDS prevalence areas;

- presence of ongoing and well-established VCT activities;

- commitment from the District Health Management Team;

- availability of space and human resources for counseling;

- ongoing programs already supported by cooperating partners; 
- districts with existing PMTCT program (phase-out within pilot districts);

- sentinel surveillance site;

- districts along the main trucking routes;

- districts with well-defined fishing areas;

- districts with seasonal workers; and

- towns with frequent cross-border trading.

Case Example: In Uganda, officials plan to scale up using a phased approach to build the capacity of districts and hospitals in providing the complete package of services (MOH Uganda 2001). Important criteria to choose sites and sequence the scale up include:

- the relative magnitude of the HIV/AIDS epidemic;

- the state of preparedness of the health facility in terms of human resource and structures;

- attainment of a geographical balance;

- the presence of partners in the form of a viable NGO; and

- the existence of other, ongoing HIV/AIDS intervention activities.

\section{Q. Once you select sites, how do you gear up for new services?}

A. To determine site readiness for introduction of PMTCT you should ensure that essential systems are in place. An example of how to do this, which you may adapt for local circumstances, is the checklist used in scaling up the PMTCT program in the Western Cape region of South Africa (see case study 2 below).

\section{IV.C. Financing and Sustainability of Scaled-Up Programs}

\section{Q. How much will it cost to scale up?}

A. Knowing costs is critical to scale-up decisions and to accurately estimate funding needs. Getting a good picture of scale-up costs is difficult because of the inherent complexities of the PMTCT approach. As a first step, find out the cost of providing PMTCT in the pilot sites. Your calculation should include both financial costs (e.g. direct purchases of supplies, staff salaries, job aids, communication materials, etc.) and the economic costs of goods and services for which there is no financial transaction (e.g. volunteer time or donated radio or television broadcast time). This will give you a rough sense of the cost of replicating the PMTCT program in similar sites. Beyond site-specific costs, scaling up will also require additional costs at the regional and national level for expanded management and supervision, coordination, and policy and communication efforts. Assuming that pilot sites are among the better-functioning $\mathrm{ANC} / \mathrm{MCH}$ sites in the country, where you plan to replicate the program you will need to budget more for strengthening basic systems and services. As an example of budgeting for district-level scale up of PMTCT, see the example from Western Cape below (case study 2). 


\section{Q. What are strategies to fund a scaled-up program?}

A. Each country's funding formula will be unique and depend on income levels, government commitment to health, and degree of engagement with the international donor community. As in the pilot phase, scaled-up programs will have to draw on both government and international donor funding. At least in the short term, commitment by international donors to PMTCT remains high and national programs can tap into existing bilateral and multilateral sources. Although clients in some countries pay fees for ANC/MCH care, none of the pilot PMTCT sites charged for core PMTCT interventions such as VCT, ARV prophylaxis, and infant feeding counseling. Although unlikely to be a major source of funding, programs may want to explore charging clients for some PMTCT services after taking into account willingness and ability to pay.

\section{Case Examples of Funding for Scale Up:}

- In Uganda, multiple sources funded scaling up including AVSI, UNICEF, Plan International, and GTZ. As part of a phased expansion plan and supply plan (2001-2004), a national framework was created that partners can buy into. No implementation takes place without approval of the National MTCT Technical Committee.

- In India, the government is financing the bulk of the scaled-up program. UNICEF will support training, quality assurance, and some monitoring and evaluation activities. UNICEF will also support a village PMTCT model in Sangli, Maharashtra.

- In Botswana, the Government has contributed over 90 percent of required funding and resources for PMTCT services. The government contribution in 2002 was roughly US\$8 million. UNICEF provides financial and technical support for curriculum development, capacity development, community mobilization, monitoring and evaluation, and provision of AZT.

Source: Desk Reviews carried out for Population Council's evaluation of pilot PMTCT programs in eleven countries. See Rutenberg et al. 2003.

\section{Q. How do I make the scaled-up PMTCT program financially sustainable?}

A. Although international donors have made funding of PMTCT a priority, the responsibility for long-term financial sustainability will eventually fall to countries. Moreover, money for PMTCT is not now and never will be sufficient to fund the fundamental health system changes that will enhance the effectiveness of PMTCT programs. National programs should begin now to develop and nurture local funding mechanisms - whether from public funds or from clients through direct payments, insurance, or community financing schemes. This should include aggressively exploring how to expand the role of the private sector (NGO and for-profit) in funding and provision of PMTCT. At the same time, countries should take steps towards increasing the efficiency of PMTCT programs. These steps include more precisely estimating 
program costs, exploring opportunities for cost recovery, and improving program management. 


\section{Scaling-Up Case Studies (Source: UNICEF 2002)}

\section{Case 1. Botswana}

By the late 1990s, Botswana faced one of the worst HIV epidemics in the world. HIV prevalence was over 35 percent in women attending antenatal clinics and 34 percent of pediatric admissions in Referral Hospitals were HIV related, with HIV responsible for 70 percent of pediatric deaths. It is estimated that 15 percent of children born every yearabout 9,500 - are infected with HIV.

The magnitude of the epidemic forced politicians to react. In September 1998, a Cabinet Memo established the PMTCT program. The first step was the establishment of a Technical Advisory Committee (TAC) that was given the task to:

- define the package of PMTCT interventions;

- develop protocols and guidelines; and

- develop an implementation plan and submit a budget to the Ministry of Health.

The TAC comprised a broad range of stakeholders including representatives from government ministries and departments such as laboratory services, food and nutrition, and primary health care and key government partners such as WHO, UNICEF, CDC, and the Harvard AIDS Institute. Hospital staff were recruited to run the program, and included a full-time pediatrician, midwife, and IEC specialist. The government launched two pilot projects, in Francistown and Gaborone, in April 1999, allocating US\$3 million annually supplemented by UNICEF funding for AZT provision.

A January 2000 program review found a number of weaknesses. Although VCT uptake was around 40 percent, only 8 percent of HIV-infected women benefited from the ARV drug intervention. Poor communication was probably a critical factor in the low ARV uptake. Although awareness of PMTCT was high among political leaders, the program needed to do more to raise awareness in and mobilize communities. The review also uncovered staff shortages at all levels, compounded by inadequate support and supervision by local management. As a result, the program did poorly in following up of women and children.

The initial recommendation of the TAC was for gradual scaling up. However, a gradual approach was not politically acceptable. Within the next sixteen months Botswana achieved 100 percent coverage of PMTCT in all health districts, facilitated by:

- the development of a preparation package that included sensitization meetings with community leaders and communities, and decentralized district-level training carried out by a private institution that trained six trainers per district, who in turn trained the health workers;

- revision of the monitoring system, and integration with existing $\mathrm{MCH}$ registers and information systems; 
- central procurement and distribution of PMTCT supplies including drugs, lockable cabinets, infant formula, and monitoring tools and integration with the Central Medical Stores;

- preparation of districts before launching the program including, at the district level, having at least one trained midwife counselor and PMTCT supplies in all clinics offering the service; and within hospitals, having at least two trained midwife counselors, one trained laboratory technician, one trained pharmaceutical technician and all supplies including laboratory equipment and reagents;

- linkages with other services, for example referral to an ARV clinic for HAART, and referrals for women counseled and tested outside government institutions.

The accelerated scaling-up process has caused a number of problems:

- Referral from health facilities for supportive counseling is still weak;

- The need to improve the quality of counseling and lessen burnout of counselors; and

- Spillover of formula feeding into the HIV-negative population.

However, the dynamism created by the success of the scaling up process has allowed program managers to respond innovatively. These responses have included supervision and mentoring of counselors, meetings to debrief counselors, refresher training, and counseling of counselors for management of the burnout syndrome.

The program responded to personnel shortages with a new initiative that recruits and trains community workers to do take on some of the counseling burden. The initiative has brought many more counselors into the program. Finally, the program has developed and is now carrying out a comprehensive infant feeding policy to actively promote safe infant feeding practices in the community. 


\section{Case 2. Western Cape Province of South Africa}

The Western Cape is one of nine provinces in South Africa, with a population of about four million people. Although one of the last areas to be heavily affected by HIV/AIDS, by the late 1990s it had the country's fastest-growing epidemic, reaching 7 percent of pregnant women by 2000 .

Two pilot PMTCT sites were started in January 1999 in Khayelitsha, a township of 400,000 people in Cape Town. Despite being in a wealthy province, the legacy of apartheid meant that township services were not much better than in many other poor urban areas. The infant death rate is over 50 per thousand and about one in five women attending antenatal clinics is HIV-positive.

Over eight months, senior health managers met fortnightly to plan and implement the pilot PMTCT program. The program was well accepted by the community, with no drop off in ANC attendance and high quality training from a local NGO. The program also established vastly improved relationships between the different levels of the service. For the first time, labor wards and local clinics agreed on referral pathways and communication. However, the added burden of counseling was too heavy and the quality of counseling and record keeping slipped. In one of the pilot site, for example, acceptance of VCT was less than 50 percent. The fragmented nature of the health system also hampered drug and equipment supplies. Managers decided to reinstitute the fortnightly monitoring meetings with participation from all the role players at the local, district, regional, and provincial level. This monitoring body resolved many important issues, including the decision to contract a local NGO to provide lay counselors and relieve the counseling burden. By the end of the second year, the program showed significant improvements in management and client uptake.

The success of the two pilots created demand from neighboring districts and local politicians for scaling up the project. Scale up began in January 2001, first targeting highprevalence areas. The planning period for implementation progressively shortened and is now down to three months; within two years the program covered 95 percent of the province. The development of clinical guidelines, a simple preparation checklist (see below) and a budget outline (see below) have helped in shortening preparation time. A provincial-level management committee outlines guidelines, supports the regions, and handles procurement, and manages quality control. Four regional HIV coordinators control the budget and convene separate regional level meetings to monitor implementation. Officials attribute the success of the scale up a number of factors including:

- active involvement of senior management;

- the existence of well-functioning systems;

- high quality training for counselors;

- an active civil society coalition that raised awareness of the program; and

- adequate resources for implementation. 


\section{PMTCT Site Readiness Check List Western Cape}

In preparation for the roll out of PMTCT in a district, the Provincial/Regional Department of Health convenes a meeting with role players in the district (health managers and staff of the antenatal services, obstetric services and well bay clinics).

The purpose of the meeting is to explain the protocols and to ensure "buy in" from all concerned. Roll out also entails deciding whether to identify one person to manage the process or to appoint a few teams to shepherd different tasks. These tasks include:

\section{BUDGET}

A business plan and budget is to be drawn up, based on the district's antenatal bookings and HIV prevalence.

\section{APPOINTMENT OF ADDITIONAL STAFF}

Additional nursing staff may be required and the process for the advertisement and filling of these posts must be put into place.

A number of lay counselors (one lay counselor per 1000 bookings/per annum) will be employed to offer pre-test and post test counseling. An appropriate NGO is approached to take on the employment of lay counselors and contracts for funding are signed.

\section{TRAINING OF STAFF}

All staff who will participate in implementing the program are expected to attend relevant courses regarding PMTCT.

The following courses are made available:

AIDS Awareness \& PMTCT: all medical and nursing staff, lay counselors, and support staff (Clerical and cleaning staff);

HIV rapid testing: all medical and nursing staff;

Protocols i.e. nevirapine, Labor ward practices etc: all medical and nursing staff; Infant feeding: all lay counselors and nursing staff;

Registers and Monitoring and Evaluation: all lay counselors and nursing staff.

\section{STORE SUPPLIES}

The following stores items must be ordered and in place prior to rollout:

- Registers (proforma copies available from provincial office);

- HIV rapid tests, finger prick machines, blood lancets, swabs;

- Consent forms;

- nevirapine;

- Pellargon;

- Bactrim. 
Access to a laboratory for possible ELISA tests must be in place.

All staff must be informed of the procedures for ordering further supplies.

\section{BUILDINGS}

A space audit must be undertaken to ensure that there are adequate rooms for confidential and private counseling. A separate room for HIV testing is desirable.

Building alterations should ideally be planned and effected prior to roll out.

The 'flow' of the clinic may need to be reorganized to accommodate the PMTCT program.

\section{COMMUNITY}

The community should be informed about the program via one or more of the following:

- Local Health Forum meeting;

- Local newspaper articles;

- Public information meeting;

- Letter to general practitioners in the district;

- Letter/advertisement sent with electricity/rates bills.

\section{REFERRAL HOSPITAL}

Negotiation with the referral hospital (secondary or tertiary) needs to be undertaken, if not already involved.

Source: UNICEF 2002. 


\section{Budgeting for Scale Up}

Oostenberg, District, Western Cape

Costing Analysis of MTCT Roll-Out

September 2001

\begin{tabular}{|c|c|c|c|}
\hline Item & No. & Unit Cost & Total Budget \\
\hline Personnel Project Coordinator & 1 & 138000.00 & 138000.00 \\
\hline Professional Nurses & 2 & 98000.00 & 196000.00 \\
\hline Subtotal: & & & 334000.00 \\
\hline Laboratory Rapid Test & & & \\
\hline Mothers, Babies 9/12,18/12: & $\begin{array}{r}5200 \\
800\end{array}$ & $\begin{array}{l}10.18 \\
10.18\end{array}$ & 6150000 \\
\hline ABBOT & & & \\
\hline & $\begin{array}{r}520 \\
80\end{array}$ & $\begin{array}{l}7.49 \\
7.49\end{array}$ & 4500.00 \\
\hline WHITESTAR & $\begin{array}{r}26 \\
4\end{array}$ & $\begin{array}{l}30.55 \\
30.55\end{array}$ & 930.00 \\
\hline ELISA & & & \\
\hline Babies 9/12: & & & \\
\hline ABBOT & 600 & 10.18 & 6200.00 \\
\hline Babies 18/12: & & & \\
\hline ABBOT & 240 & 10.18 & 2450.00 \\
\hline WHITESTAR & 24 & 7.49 & 180.00 \\
\hline ELIZA & 5 & 30.55 & 160.00 \\
\hline Subtotal: & & & 75920.00 \\
\hline
\end{tabular}




\begin{tabular}{|c|c|c|c|}
\hline Item & No. & Unit Cost & Total Budget \\
\hline Drugs: & & & \\
\hline NEVIRAPINE@R21.00 & $\begin{array}{c}520 \\
80\end{array}$ & $\begin{array}{l}\mathrm{R} 21.00 \\
\mathrm{R} 21.00\end{array}$ & $\begin{array}{r}11000.00 \\
1680.00\end{array}$ \\
\hline CO-TRIMOXAZOLE & 600 & R2.28 & 12312.00 \\
\hline Children $<9 / 12$ & 240 & R2.56 & 5529.60 \\
\hline $\begin{array}{l}\text { Children } 9-18 / 12 \\
\text { Mothers (3\% at stage } 3 \& 4)\end{array}$ & 18 & $\mathrm{R} 1.68$ & 362.88 \\
\hline Subtotal: & & & 34405.00 \\
\hline Formula: PELARGON & 600 & R70.00 & \\
\hline Subtotal: & & & 252000.00 \\
\hline Project Office: & & & \\
\hline Stationery & & & 20000.00 \\
\hline Transport & & & 10000.00 \\
\hline Telephone & & & 1500.00 \\
\hline Mentoring of Staff & & & 15600.00 \\
\hline Sundries & & & 1200.00 \\
\hline Photocopy Rental & & & 2500.00 \\
\hline Subtotal: & & & 50800.00 \\
\hline Total: Institutions & & & 476005.00 \\
\hline PAWC: Transfer Payments - & & & \\
\hline Lay Counsellors & 7 & 25200.00 & 176400.00 \\
\hline Lay Counsellor Co-ordinator & 1 & 30600.00 & 30600.00 \\
\hline Total: NGO & & & 207000.00 \\
\hline Total Budget & & Grand Total: & R 935005.00 \\
\hline
\end{tabular}




\section{Note: Prevalence}

1. Prevalence of HIV-positive mothers estimated at 5\% for the costing $=260$ of 5200 births for the year 2000.

2. Durbanville Antenatal clinic: clients accommodated at this clinic $=1000(20 \%$ of Oostenberg antenatal patients per annum.)

3. Total annual bookings: Kleinvlei, Kraaifontein and Durbanville $=5000$ Karl Bremer Hospital $\quad=1000$

Total: $\quad=6000$

4. Total live births: $\quad=5200$ (year 2000)

Anticipated additional $2 \%$ doses required for mothers (who forgot tablets at home) and infants.

Source: UNICEF 2002. 


\section{Appendix A. Useful Documents}

To find out more about PMTCT you can draw on a wide range of existing documents, many of them available on the web. This appendix organizes key documents by topic.

\section{General}

The WHO's monthly survey of PMTCT publications and abstracts is complied from a regular survey of publications related to the prevention of mother-to-child transmission of HIV. They also cover abstracts presented at international conferences. They include a brief summary and comments prepared by the Bordeaux Working Group. The reports are available from:

http://www.who.int/reproductive-health/rtis/MTCT/monthly_publications/listing_mtctreports.htm

Ananworanich, Jintanat, M.D., Phongpan Vannakit, R.N., Usa Thisyakorn, M.D., Praphan Phanuphak, M.D., Ph.D. 2001. "Prevention of Mother-to-Child Transmission of HIV: Issues for South East Asia. Technical Update No. 2 April 2001." UN Regional Task Force on Prevention of Mother-to-Child Transmission of HIV, Prepared by: Thai Red Cross AIDS Research Center: Bangkok, Thailand

Bond, Ginny, Phillimon Ndubani, and Laura Nyblade. 1999. "Focus Group Discussion Guidelines II Formative Research on Mother to Child Transmission of HIV/AIDS in Zambia: Working Report of Focus Group Discussions Held in Keemba, Monze, Zambia." ZAMBART Project, School of Medicine, UTH, Zambia Mr Phillimon Ndubani, Institute for Economics and Social Research (INESOR), UNZA, Zambia., International Centre for Research on Women (ICRW), Washington.

Dabis F, Newell ML, Fransen L et al. 2000. "Prevention of mother-to-child transmission of HIV-1 in developing countries: recommendations for practice." Health Policy Planning 15:34-42.

DeCock K, Fowler MG, Mercier E et al. 2000. "Prevention of mother-to-child transmission of HIV in resource poor countries." JAMA 283:1175-82.

Healthlink Worldwide. 2000. "HIV and Safe Motherhood.” London.

Horizons Program. 2001. "Integrating HIV prevention and care into maternal and child health care settings: Lessons learned from Horizons studies." Population Council: Washington DC.

Leonard, A., P. Mane, N. Rutenberg. 2001. "Evidence for the importance of community 
involvement: implications for initiatives to prevent mother-to-child transmission of HIV." Population Council, ICRW, and Glaxo Wellcome: Washington DC.

Nyblade, L., M.L Field-Nguer. 2001. Women, communities, and the prevention of mother-to-child transmission of HIV: Issues and findings from community research in Botswana and Zambia." Population Council, ICRW, and Glaxo Wellcome: Washington DC.

Healthlink Worldwide. 2000. "HIV and Safe Motherhood.” London.

Horizons Program. 2001. "Integrating HIV prevention and care into maternal and child health care settings: Lessons learned from Horizons studies." Population Council: Washington DC.

Leonard, A., P. Mane, N. Rutenberg. 2001. "Evidence for the importance of community involvement: implications for initiatives to prevent mother-to-child transmission of HIV." Population Council, ICRW, and Glaxo Wellcome: Washington DC.

Marseille, E., and J.G. Kahn. 2001. "Manual for use of a Cost-effectiveness Tool for evaluating antiretroviral drug and substitute feeding interventions to prevent mother-to-child transmission of HIV. Version 1.0." Field test draft version. UNAIDS: Geneva

McIntyre, James. 1998. "HIV in Pregnancy: A Review.” World Health Organization, UNAIDS: Geneva.

Nyblade, L., M.L Field-Nguer. 2001. Women, communities, and the prevention of mother-to-child transmission of HIV: Issues and findings from community research in Botswana and Zambia." Population Council, ICRW, and Glaxo Wellcome: Washington DC.

Preble E and Piwoz E. 2001. "Prevention of mother-to-child transmission of HIV in Africa: Practical guidance for programs." Support for Analysis and Research in Africa (SARA) Project, Washington DC. Available from SARA, sara@,aed.org, 44 pages.

Rutenberg, N., M.L Field-Nguer., L. Nyblade. 2001. "Community involvement in the prevention of mother-to-child transmission of HIV: Insights and recommendations." Population Council, ICRW, and Glaxo Wellcome: Washington DC.

UNAIDS. 2000.” Mother-to-child transmission of HIV: Technical update." Geneva.

UNAIDS. 1999. "Prevention of HIV transmission from mother to child: Strategic options." Geneva. 
UN General Assembly Special Session on HIV/AIDS (UNGASS). 2001. "Global Crisis Global Action" Declaration of Commitment on HIV/AIDS.” New York. June 2001.

UNICEF, UNAIDS. 1998. "Vertical Transmission of HIV: Rapid Assessment Guide." Geneva.

UNICEF/UNAIDS/WHO/UNFPA. 2000. "African Regional Meeting on Pilot Projects for the Prevention of Mother-to-Child Transmission of HIV." Botswana.

UNICEF. 2002. "Ensuring Secure and Reliable Supply and Distribution Systems in Developing Countries in the Context of HIV/AIDS and PMTCT: Prevention of Mother to Child Transmission of HIV: Checklist for Developing a Supply Management Strategy.” Draft paper. New York.

UNICEF. 2002. "Technical Working Note: Preventing mother-to-child transmission of HIV." New York.

UNICEF, UNDP, UNFPA, UNDCP, UNESCO, WHO, WORLD BANK, Joint United Nations Programme on HIV/AIDS. 1999. "Prevention of HIV transmission from mother to child: Strategic options." Geneva.

UNICEF. 2002 "Programme Working Note: Preventing mother-to-child transmission of HIV.” Draft Paper. New York.

Wiktor SZ, Ekpini E, Nduati RW. 1997. "Prevention of mother-to-child transmission of HIV-1 in Africa." AIDS 11 (suppl. B): S79-S87.

WHO. 2000. "New data on the prevention of mother-to-child transmission of HIV and their policy implications: Conclusions and recommendation." Geneva.

WHO, UNICEF, UNAIDS. 1999. "Statement on current status of WHO/UNAIDS/UNICEF Policy Guidelines.” Geneva.

\section{PMTCT Program Job Aids}

Western Cape Province, South Africa has developed standardized protocols for counseling and testing, maternal and neonatal care, and pediatric follow-up to educate and instruct health care workers. There are two editions of the protocol. A comprehensive edition details policy and practice in text and flowcharts. It captures operational aspects of program implementation including detailed explanations of logbooks and monitoring forms. This edition is intended for site managers and staff training. A summary edition details procedures for clinic personnel and is intended for active use by clinic staff. There are flowcharts for VCT, labor and delivery care, postnatal administration of nevirapine to the baby, pediatric follow-up and pediatric testing. The protocols have proven effective in 
numerous field settings and can be adapted to suit the needs of a site. Available on provincial web site.

The Regional Center for Quality of Health Care in Uganda has developed a job aid for Primary Health Care Workers "Counseling Mothers on Infant Feeding for the Prevention of Mother to Child Transmission of HIV" (2003). This job aid accompanies training on infant feeding for PMTCT. It was designed to reduce formal training time and reliance on memory to perform what is expected on the job. It is written using a methodology that improves on-the-job performance of health workers. This job aid is written at the primary 6 reading level to ensure ease of reading for all levels of health care workers.

UNICEF has developed ANC and PMTCT Talking Points for Counselors. These cover transmission and prevention of HIV/AIDS, VCT, infant feeding, postnatal care and infant testing, family planning, and living positively with and without HIV/AIDS. (To be available for distribution on CD by June 2003.)

\section{VCT}

Family Health International (FHI). 2002. "Voluntary Counseling and Testing (VCT) and Young People: A Summary Overview.” Washington DC.

FHI. n.d. "UNICEF's Role in VCT for Young People, Children, Pregnant Women and their Partners." Washington DC.

FHI. 2002. "A Guide to Establishing Voluntary Counseling and Testing Services for HIV." Washington DC.

Horizons Program. 2001. "HIV Counseling and Testing: Will it Attract Youth?" Population Council: Washington DC.

UNAIDS. 2002. "HIV voluntary counseling and testing: A gateway to prevention and care." Geneva.

UNAIDS. 2001. "The Impact of VCT: A global Review of Benefits \& Challenges." Geneva.

UNAIDS. 2001. "Counseling and Voluntary HIV Testing for Pregnant Women in High Prevalence Countries: Elements and Issues." Geneva. http://www.unaids.org/publications/documents/health/counselling/Couns2001E.pdf

UNAIDS. 2000. “Opening up the HIV/AIDS epidemic: Guidance on encouraging 
beneficial disclosure, ethical partner counselling and appropriate use of HIV casereporting." Best Practice Collection. Geneva.

http://www.unaids.org/publications/documents/epidemiology/surveillance/JC485Opening-E.pdf

UNAIDS. 2000. "VCT Technical Update." Geneva. www.unaids.org/www.root/publications/order.html\#tech (go to TU 17)

UNAIDS. n.d. "UNAIDS Policy on HIV Testing and Counseling.” Geneva.

UNAIDS. n.d. "Introduction to Counseling and Voluntary Counseling and Testing." Geneva. www.unaids.org/bestpractice/collection/subject/health/cvc.html

UNAIDS. 1999. "Knowledge is power: Voluntary HIV Counseling and Testing in Uganda. Case Study." Geneva.

UNAIDS, WHO. 1999. "Operational characteristics of commercially available assays to determine antibodies to HIV 1 and/or HIV 2 in human sera." Geneva.

UNAIDS, CDC, USAID, WHO. (2001). "UNAIDS/CDC/USAID/WHO Guidelines for using HIV Testing Technologies in Surveillance, Selection, Evaluation and Implementation." Geneva.

UNICEF, UNDP, UNFPA, UNDCP, UNESCO, WHO, WORLD BANK, UNAIDS, United Nations. 2000. "UNAIDS Technical update May 2000: Voluntary Counselling and Testing (VCT)." Geneva.

US Centers for Disease Control and Prevention. n.d. "Using rapid testing in HIV Counseling and Testing Programs." Atlanta.

US Centers for Disease Control and Prevention. n.d. "Rapid HIV Tests, Questions and Answers." Atlanta. www.cdc.gov/HIV/DHAP.htm

US Centers for Disease Control and Prevention. n.d. "Rapid HIV tests: Issues for Counselors Providing HIV Prevention Counseling." Atlanta. www.cdc.gov/hiv/pubs/RT/rapidct.htm

US Centers for Disease Control and Prevention. 1998. "HIV Partner Counseling and Referral services: Guidance.” Atlanta. www.cdc.gov/hiv/pubs/PCRS.pdf

WHO. 2001. "Clinical Guides for the management of pregnant women with HIV Infection: Voluntary Counseling and Testing for HIV in Pregnant Women: Field Testing Guide." Geneva.

WHO, UNAIDS. 2001. "WHO/UNAIDS Technical Consultation on Voluntary HIV 
Counselling and Testing: Models for Implementation and Strategies for Scaling of VCT Services.” Harare, Zimbabwe. 3-6 July 2001

WHO, HIV/AIDS and Sexually Transmitted Infections Initiative. 1999. "Voluntary Counseling and Testing for HIV Infection in Antenatal Care: Practical considerations for implementation." Geneva. Available from the WHO.

\section{Short course antiretroviral drugs for PMTCT}

Kanshana S, Thewanda D, Teeraratkul A, Limpakarnjanarat K, Amornwichet P, Kullerk N, Akksilp, S, Sereesittipitak V, Mastro TD, Simonds RJ. 2002. "Implementing short-course zidovudine to reduce mother-infant HIV transmission in a large regional pilot program in northeastern Thailand.” AIDS;14:1617-23. Results of a regional program and its evaluation.

UNAIDS. 2001. "Nevirapine donation for prevention of mother-to-child transmission of HIV. Geneva.

UNAIDS. 2001. "Prevention of mother-to-child transmission of HIV: Thai red cross Zidovudine donation program." Geneva.

UNAIDS. 2000. "Use of Nevirapine to reduce mother-to-child transmission of HIB (MTCT)." Geneva.

WHO. 2001. "Prevention of Mother-to-Child Transmission of HIV: Selection and Use of Nevirapine: Technical Notes." Geneva.

WHO. 2000. "Safety and tolerability of Zidovudine." Geneva.

WHO. 1998. "Recommendations on the safe and effective use of short-course ZDV for prevention of mother-to-child transmission of HIV." Weekly Epidemiological Record. (73:41), 313-320.

WHO. n.d. "Booklet on WHO bulk procurement scheme." Geneva. Available fomr vercauterng@who.int .

\section{Infant Feeding}

Department of Health South Africa. 2002. "Breastfeeding and HIV: An information booklet for health workers in South Africa." Provincial Administration of theWestern Cape, Department of Health, Nutrition, Sub-Directorate, Cape Town Breastfeeding Liaison Group and the University of the Western Cape, School of 
Public Health, January 2002. Available from regional health offices, South Africa, 24 pages

Department of Health, South Africa, and UNICEF. 2000. "South African breastfeeding guidelines for health workers." Pretoria, South Africa. Available from The Director General, Department of Health, Private Bag X828, Pretoria 0001, South Africa.

De Wagt A, Henderson P and Mason E. 2000. "Assessment tool for measuring the outcome of the HIV and infant feeding counselling course." Draft paper. Nairobi. Available from UNICEF (adewagt@unicef.org) or WHO-AFRO (emason@whoafr.org).

Department of Paediatrics and Child Health, University of Natal. n.d. "Infant feeding choices for HIV-infected women." Durban. Available from the Department of Paediatrics and Child Health, University of Natal, Durban, South Africa.

Ministry of Health and Child Welfare, National Nutrition Unit, Zimbabwe. 2000. "Infant feeding and HIV/AIDS: Guidelines for health workers in Zimbabwe." Harare. Available from National Nutrition Unit, Ministry of Health and Child Welfare, National Nutrition Unit, PO Box CY1122, Causeway, Harare, Zimbabwe.

Regional Centre for Quality of Health Care (RCQHC). 2003. "Counseling Mothers on Infant Feeding for the Prevention of Mother to Child Transmission of HIV Regional Centre for Quality of Health Care: A job-aid for Primary Health Care Workers." (REDSO/ESA).

UNAIDS, UNICEF and WHO. n.d. "HIV and infant feeding: A Policy Statement developed collaboratively by UNAIDS, UNICEF and WHO." Geneva.

UNAIDS, UNICEF and WHO. Forthcoming, 2003. "HIV and Infant Feeding: A Guide for Health Care Managers \& Supervisors," Geneva.

UNICEF has developed Infant Feeding $Q \& A$ Tool for Counselors: Answers to questions commonly asked by mothers and their families (To be available for distribution on CD by June 2003.)

UNICEF. 2002. "Infant Feeding and mother to child transmission of HIV: technical guidance note." New York.

WHO. 2002. "Breastfeeding and replacement feeding in the context of mother-tochild transmission of HIV." Geneva.

WHO. 2001. "Effect of breastfeeding on mortality among HIV-infected women." Geneva. 
WHO. 2000. "HIV and infant feeding counseling: A training course." Geneva, WHO/FCH/CAH/00.2-6. Available from Child and Adolescent Health and Development, WHO, Geneva, as hard copy or CD, approximately 400 pages for all materials (English, French).

WHO, UNAIDS. 1998. "HIV and Infant Feeding Guidelines for decision-makers." Geneva. http://www.unaids.org/publications/documents/mtct/infantpolicy.html

WHO/AED, HIV and Infant Feeding Counseling cards.

\section{Human Resources and Capacity Building}

The following documents are listed in a WHO inventory of documents and tools on PMTCT. This inventory lists titles and provides a summary of the information contained.

Kenya PMTCT Project. 2002. "MTCT Training Curriculum.” Available from: Horizons Program/Population Council Training curriculum (PDF): http://www.popcouncil.org/horizons/pmettc.html

Meerkotter A, S Bullington, T.Young, et al. 2001. "Mother-to-child transmission of HIV: A guide for health workers and HIV/AIDS trainers." Treatment Action Campaign/AIDS Law Project, South Africa. Available from Treatment Action Campaign, http://www.tac.org.za/(select documents, select mother-to-child transmission), 46 pages.

Ndondo, Noziqhu Tatiana. 2001. "Preventing mother-to-child transmission of HIV: A training manual for health care providers. South Africa." Reproductive Health Alliance Europe and Perinatal HIV Research Unit. Soweto. Available from: Reproductive Health Alliance, info@,rhalliance.org, or Perinatal HIV Research Unit, info@hivsa.com, 64 pages .

Ministry of Health, Ghana. 2001. "Prevention of mother-to-child transmission of HIV in Ghana: Manual for health workers." Draft paper. Accra. Available from: Dr. Henrietta Odoi-Agyarko, Ministry of Health, Accra, Ghana, 35 pages.

Mother-To-Child Transmission of HIV (MTCT) Working Group, Central Board of Health, Zambia. 2001. "Prevention of mother-to-child transmission of HIV: A trainee's manual." Hector Chiboola, Chipepo Kankasa, Maureen Chisembele, Chilimba Hamavhwa, Dorothy Nthani, Milika Zimba ed. Lusaka. Available from: MTCT Secretariat, mtct@zamnet.zm, 173 pages.

MTCT Working Group/Ministry of Health and Cooperating Partners: UNICEF, WHO, UNAIDS, JICA, Norad, USAID. 2000. “Trainers' Manual: Intervention for the 
reduction of MTCT of HIV infection in Zambia." Lusaka. Available from MTCT Secretariat, mtct@zamnet.zm, 80 pages.

UNAIDS. 2000. "Caring for Carers: Managing stress in those who care for people living with HIV/AIDS. Case Study." Geneva.

www.unaids.org/publications/documents/health/counselling/Caring_carers.pdf

UNICEF. 1999. "Prevention of mother-to-child transmission of HIV: An integrated training manual, Volumes I and II." Dar es Salaam. Available from Prevention of MTCT Coordinator, yipuge@much.ac.tz, Vol. I = 43 pages plus annexes, Vol. II $=70$ pages plus annexes.

\section{Antenatal Care, Safe Labor and Delivery, and Post Partum Care}

Moore, Mona. 2003. "A behavior change perspective on integrating PMTCT and Safe Motherhood Programs: A discussion paper." The Change Project: Washington DC.

WHO, Reproductive Health and Research/ Integrated Management of Pregnancy and Childbirth (IMPAC).2002. "The essential care practice guide for pregnancy and childbirth.” Draft paper, Essential Care Series. Geneva. Available from WHO, Geneva, 172 pages plus annexes.

WHO Regional Office for Africa Department of Reproductive Health and Research, Family and Community Health. 2001. "Clinical guides for the management of pregnant women with HIV infection (field testing version).” WHO/RHR/01.23, 24, 25, 26. Geneva. Available from WHO-AFRO, hoffe@whoafr.org.

\section{Communications, Including Stigma}

Shari Cohen. 2002. "HIV/AIDS/MTCT Stigma and Discrimination Field Experiences and Research from Africa, Asia \& Ukraine.” UNICEF: New York.

Panos Institute. 2001. "Stigma, HIV/AIDS and prevention of mother-to-child Transmission: A pilot study in Zambia, India, Ukraine and Burkina Faso." London.

UNICEF. 2002. “Communication for PMTCT: Introduction to UNICEF's Communication for Development Model.” New York.

UNICEF. n.d. "Baseline Indicators: Communication for PMTCT.” New York. Research tools

Mukuka C, and R Siyandi. 1999. "The Mother to Child Transmission Intervention: A Report on the Formative Research Conducted in Chipata Health Centre and its 
Catchment Area. " Zambia Central Board of Health, and National Food and Nutrition Commission: Lusaka.

UNICEF. 2002. "Developing Communication Strategies for PMTCT: UNICEF's

Communication Initiatives in Africa and Asia. Lessons Learned.” New York.

\section{Monitoring and Evaluation}

Amornwichet P, Teeraratkul A, Simonds RJ, Naiwatanakul T, Chantharojwong N, Culnane M, Tappero J, Kanshana S. 2002. "Preventing mother-to-child HIV transmission-results from the first year of Thailand's national program." $J A M A ; 288: 245-8$. Results from the national monitoring system.

Department of Health, Ministry of Public Health, Thailand. 2000. "Evaluation of Voluntary Counselling and Testing in the National Prevention of Mother to Child Transmission Programme in Thailand Department of Health.” Bangkok.

Hodge, M.J. 2002. "Evaluating UNICEF-supported PMTCT Programmes." Poster Presentation at XIV International AIDS Conference, Barcelona.

Kanshana S, R.J. Simonds. 2002. "National program for preventing mother-child HIV transmission in Thailand: Successful implementation and lessons learned." AIDS. 2002;16:953-959.

Naiwatanakul T, Chantharojwong N, Amornwichet P, Teeraratkul A, Culnane M, Kanshana S, Tappero JW, Simonds RJ. 2002. "Developing a perinatal HIV intervention monitoring system for evaluating a large-scale prevention of mother to child HIV transmission program in Thailand." Abstract from XIVth International Conference on AIDS, Barcelona, July 2002. A description of the national monitoring system development.

Nolan M, Simonds R, Thewanda D, Naiwatanakul T, Teeraratkul A, Kanshana S. 2001. "Health and social impact of a perinatal HIV prevention program, Thailand." Abstract 325 from the Third Conference on Global Strategies for the Prevention of HIV Transmission from Mothers to Infants, Kampala, September 9-13, 2001.

Nolan M, Simonds R, Thewanda D, Naiwatanakul T, Teeraratkul A, Kanshana S. 2001. "Uptake and acceptability of AZT and formula for perinatal HIV prevention, Thailand." Abstract 326 from the Third Conference on Global Strategies for the Prevention of HIV Transmission from Mothers to Infants, Kampala, September 9-13, 2001.

UNICEF/UNAIDS/WHO. 2001. "Local monitoring and evaluation of the integrated prevention of mother-to-child HIV transmission in low-income countries." Draft paper. New York. 
UNICEF. n.d. "MTCT Aggregated Data Flow." New York.

UNICEF. n.d. "UNICEF MTCT Monitoring and Evaluation Plan" Geneva.

UNICEF n.d. “UNICEF MTCT Monitoring Form.” Geneva.

US Centers for Disease Control. 2001. "Evaluation of a regional pilot program to prevent mother-infant HIV transmission - Thailand, 1998-2000." MMWR. 50:599-603.

\section{Regional Policies and Country Guidelines}

Department of Health, Provincial Administration of the Western Cape. 2002. "Prevention of Mother to Child Transmission of HIV: Full Protocol." Cape Town. Available from HIV/AIDS Directorate, Department of Health, Provincial Administration of the Western Cape, 4 Dorp Street, 8000, Cape Town, South Africa.

Intercountry Team, UNICEF East Asia Pacific Regional Office, and the WHO: Bangkok, Thailand. 1999. "Large-scale Implementation for the Prevention of Mother To Child Transmission of HIV Issues for South East Asia and the Pacific: Should we go for it? How? November 1999 Technical Update No. 1.” Bangkok.

LINKAGES, USAID. 2002. "Prevention of Mother-to-Child Transmission of HIV in Asia: Practical Guidance for Programs." June 2002. Washington DC.

Ministere de la Sante Publique, Comite National de Lutte contre le SIDA. Guide technique pour la prevention de la transmission mere-enfant du VIH au Cameroun. Yaounde, June 2001. Available from: The Permanent Secretariat, National AIDS Control Committee, P.O Box 1459 Yaounde, Cameroon, 111 pages (French and English).

Ministry of Health and Population, Malawi. 2000. "Guidelines for health workers for implementing interventions to reduce mother-to-child transmission of HIV in Malawi.” Draft paper. Lilongwe, Malawi, June 9, 2000. Available from Reproductive Health Unit, Ministry of Health and Population, PO Box 30377, Lilongwe 3, Malawi, 36 pages.

Ministry of Health, Botswana. 2001. "Counseling for prevention of mother-to-child transmission of HIV: The VCT/PMTCT Information Handbook." Gaborone, Botswana. Available from Family Health Division, Ministry of Health, Gaborone, Botswana, 62 pages.

Ministry of Health, Mauritius, Quality of Life, AIDS Division. 2002. "Management guidelines for the prevention of mother-to-child transmission of HIV." Mauritius, Available from: Ministry of Health, Mauritius, 14 pages. 
Ministry of Health, Uganda. 2001. "Example of a National PMTCT Policy: Policy for Reduction of the Mother-to-Child HIV Transmission in Uganda." Kampala.

Ministry of Health, Uganda. 2001. "Policy for Reduction of the Mother-to-Child HIV Transmission in Uganda." Kampala.

Ministry of Health, Rwanda. 1998. "Reduction of the rate of mother-to-child transmission, Rwanda. Notebook of technical procedures for follow-up of women and infants." Kigali. Available from PMTCT Coordinator, Ministry of Health, PO Box 84, Kigali, Rwanda, sshengero@yahoo.fr, 30 pages (French).

Ministry of Health, Rwanda. n.d. "Module de formation en PMTCT/Rwanda: la transmission due VIH de la mere a l'enfant et ses determinants." Kigali, Rwanda. Available from PMTCT Coordinator, Ministry of Health, PO Box 84, Kigali, Rwanda, sshengero@yahoo.fr, 16 pages (French).

\section{Scaling Up}

Advance Africa. n.d. "Ten Dimension of Scaling Up Reproductive Health Programs." http://www.advanceafrica.org/pages/scaleup_10_dimensions.html

deJong, Jocelyn. 2001. A Question of Scale. The Challenge of Expanding the Impact of Nongovernmental Organizations' HIV/AIDS Efforts in Developing Countries. http://www.aidsalliance.org/_docs/_languages/_eng/_content/_3 publications/do wnload/Research/A\%20Question $\% 20$ of $\% 20$ Scale.pdf

Engenderhealth and IPAS. 2000. "Taking Postabortion Care Services to Scale. Report of an International Workshop Held in Mombassa, Kenya." Mombassa.

Ministry of Health of Uganda. 2001. "Prevention of Mother to Child HIV Transmission. Scale-up Plan 2001-2005.” Kampala.

Siwale, Margaret. 2001. "PMTCT Communications: Strategies in Scaling Up Using the Zambia Experience." Presented by Dr. Siwale at "Scaling Up of PMTCT" A Satellite Meeting of the Third Global Strategies Conference on PMTCT Kampala, Uganda, September 2001

Smith, Janet and Charlotte Colvin. 2000. "Getting to Scale in Youth Adult Reproductive Health Programs." Washington, DC: Focus on Young Adults. http://www.pathfind.org/pf/pubs/focus/guidesandtools/PDF/Scalingtext1.PDF

UNAIDS. 2000. "Prevention of mother-to-child transmission of HIV meeting: Draft recommendations for scaling up interventions in pilot countries." Gaborone, Botswana. http://www.unaids.org/publications/documents/mtct/Gaborone.doc 
UNICEF. 2002. "Draft Report of PMTCT Scaling-Up Meeting. Report of a Meeting Held in Mombassa, Kenya." 


\section{Appendix B. References}

Baek, Carolyn, Marina Xioleth Rodriguez, and Luis Roberto Escoto, 2002, Report on the Qualitative Rapid Assessment of the UN-Supported PMTCT Pilot Program in Honduras August 26-30, 2002

Baggaley R, et al, year?: Men make a difference: Involving Fathers in the Prevention of Mother-to-Child HIV Transmission.

Besser, MJ 2002: Mothers-to-mothers-to-be: peer counseling, education and support for women in pregnancy in Cape Town, South Africa. Barcelona conference abstract MoOrF1031

Boswell, Deborah and Rachel Baggaley. 2002. Voluntary Counseling and Testing and Young People: A Summary Overview. Family Health International.

Campbell, I. and A. Rader. 1995. HIV Counselling in developing countries: the link from individual to community counselling for support and change. British Journal of Guidance and Counselling Vol. 23, No.1.

Chaovarindr U. 2002: Acceptance of and adherence to zidovudine and infant formula for preventing mother-to-child HIV transmission, Bangkok, Thailand. Barcelona conference abstract ThOrD1430.

Chersich, M.F et al. 2002. A model for postpartum voluntary counselling and testing $(P P-V C T)$ in a resource constrained setting, Barcelona conference abstract TuPeF5399

Dabis F 2002: Effectiveness of a short course of AZT+nevirapine to prevent MTCT: The Ditrame Plus ANRS 1201 Project Abidjan Cote d'Ivore. Barcelona conference abstract ThOrD 1428.

Gosh S et al. 2002: Social marketing approach to voluntary counseling and testing (VCT) in Zimbabwe. Abstract No. MoPeF 4040 Barcelona International conference on AIDS.

Green, Cynthia P. 1999. Improving Breastfeeding Behaviors: Evidence from Two Decades of Intervention Research, LINKAGES (Breastfeeding, Complementary Feeding, and Maternal Nutrition Program) Project, Washington, DC.

Horizons 2001. Integrating HIV Prevention and Care into Maternal and Child Health Care settings: Lessons learned from Horizons Studies. 
Inwani I 2002:_Labor room acceptance of HIV testing among un-booked post-delivery women at Kenyatta National Hospital (KNH), Nairobi, Kenya. Barcelona conference abstract TuPeF 5392

Kankasa, C et al. 2002. Report on the Rapid Assessment of the UN-supported PMTCT pilot program in Zambia.

Kenya PMCT Project. 2002. PMCT Training Curriculum. Population Council, Nairobi, Kenya.

Kibenge $\mathrm{R}$ et al. 2002: Voluntary counseling and testing as an integral part of antenatal services in Mulago hospital Uganda. Abstract No TuPeD 4974 Barcelona International conference on AIDS.

Kuhn L 2002:Uptake of interventions to reduce MTCT" nevirapine and Exclusive Breastfeeding in the Zambia Exclusive Breastfeeding study (ZEBS). Barcelona conference abstract TuOrB 1176.

Lara M 2002: Costing voluntary counseling and testing services in Kenya: a multi-centre exercise. Barcelona conference abstract TuPeE5161

LifeLine/ChildLine 2002.

National Food and Nutrition Commission (Zambia)/Linkages/SARA/USAID. 1999. "Ndola demonstration project to integrate infant feeding counseling and HIV voluntary testing into health care and community services: HIV and infant feeding." Formative research report. Lusaka: Linkages.

David McCoy, Mitch Besser, Ronel Visser, and Tanya Doverty. February 2002. Interim Findings on the national PMTCT Pilot Sites: Lessons and recommendations. ISBN\#: 1-919743-64-2. Website http//www.hst.org.za

Moore, Mona. 2003. A Behavior Change Perspective on Integrating PMTCT and Safe Motherhood Program: A Discussion Paper. Washington, DC: The CHANGE Project.

Morrow, Ardythe L. et al. 1996. Evaluation of the Effectiveness of Home-Based Counseling to Promote Exclusive Breastfeeding Among Mexican Mothers. Wellstart International, Expanded Promotion of Breastfeeding Program, Washington, D.C

Ministry of Health of Uganda. 2001. Prevention of Mother to Child HIV Transmission. Scale-up Plan 2001-2005. 
Moyo S et al. 2002: Feasibility of HIV/AIDS counseling for pregnant women using community volunteers: Experience from Zimbabwe. Barcelona conference abstract: ThPeF8027.

Mukwashi P 2002: Psychosocial and economic support through women's associations, Zimbabwe. Barcelona conference abstract: TuPeG 5674

Mutunda A 2001: Successful Male Involvement in Prevention of Mother to Child Transmission: a Case Study from Keemba, Zambia. Abstract presented in Burkina Faso ICASA Dec 2001.

Ngidi AC 2002: Acceptability and limitations of HIV group pre-test counseling for pregnant women in rural KwaZulu Natal, South Africa. Barcelona conference abstract TuPeF 5414

Noba AV 2002 Prevention of mother to child transmission of HIV (PMTCT) including community mobilization and enhanced care and support: experience from Abidjan Cote d'I'vore. Barcelona conference abstract: WePeF 6730

Nogueira SA 2002: Changes over time in the use of antiretrovirals to prevent vertical transmission of HIV. Rio de Janeiro Brazil. Barcelona conference abstract WePeB5912.

Oberzaucher N, and R Baggaley. 2002. "HIV Voluntary Counselling and Testing: a gateway to prevention and care Five case studies related to prevention of motherto-child transmission of HIV, tuberculosis, young people, and reaching general population groups" UNAIDS: Geneva.

Onyango S 2002 Implementing PMTCT program in Uganda: Challenges and lessons learned. Abstract No TuPeF 5404Barcelona International conference on AIDS

Peffer, Dimitri, Nafissa B. Osman, and Paula Vaz. 2002. "Cost-benefit analysis of a PMTCT program in Mozambique." Evaluation and Program Planning Vol 25, No 4: 433-445.

Pham, P, A. Musemakweri, and H. Stewart. 2002. Report on the Rapid Assessment of the UN-supported PMTCT pilot program in Rwanda.

Population Council. 2002. Desk Reviews of PMTCT Pilots in Botswana, India, Ivory Coast, Kenya, Rwanda, Tanzania, and Uganda.

Programme Review Team, PMTCT Advisory Group and Infant Feeding Study Group. 2002. "Prevention of mother-to-child transmission: evaluation of a pilot programme and a follow-up study of infant feeding practices during the scaled-up programme in Botswana." Evaluation and Program Planning Vol 25, No. 4: 421431. 
Pulerwitz, J, et al, 2002: Involving Men in Maternal and Child Health to Reduce HIV in Zimbabwe.

Quaghebeur ASM et al. 2002: Implementation of MTCT intervention project with NVP in Mombasa Kenya. Abstract No ThPpD 2149 Barcelona International conference on AIDS.

Rosenfield A et al. 2002 The MTCT Plus Program: A major initiative to provide care and treatment to HIV-infected women and their children. Barcelona conference abstract: MoPeB3244

Rutenberg, Naomi, Carolyn Baek, Sam Kalibala, and James E. Rosen. 2003. Evaluation of UN-supported Pilot Projects for Prevention of Mother-to-Child Transmission of HIV: Overview of Findings. Washington, DC: Population Council (forthcoming).

Rutenberg, N. et al, 2002: Involving Men in the Prevention of Mother-To-Child Transmission of HIV in Kenya Barcelona conference abstract

Safe Motherhood Initiative Fact Sheet http://www.safemotherhood.org/init_facts.htm

Sarna, A 2002: PMTCT Evaluation: Report on Discussions with National AIDS Control Organization and Visits to Two Pilot Program Studies.

Shutes E, et al, 2002: Involvement of men in programs to prevent mother-to-child transmission of HIV. Barcelona Conference Abstract: MoOrF1032

Smith M 2002: Benefit of pre-counseling video and group discussion in the prevention of MTCT, Botswana, 2001. Barcelona conference abstract: TuPeF 5389

Shyamprasad S 2002: AZT, 3TC, nevirapine and CS in prevention of MTCT in Chennai India. Barcelona conference abstract ThPpD 2145

Stocking L et al. 2002 Improvement in acceptance of HIV testing among pregnant women following the introduction of a program to prevent MTCT in Botswana Abstract No TuPeF 5410 Barcelona International conference on AIDS

Sweat M 2000: Cost-effectiveness of voluntary HIV-1 counseling and testing in reducing sexual transmission of HIV-1 in Kenya and Tanzania. The Lancet. Vol. 356: 11321. July 8, 2000.

Terris-Prestholt F 2002. The cost-effectiveness of the Zambian ProTest Project: Integrating VCT with TB activities. Barcelona conference abstracWeOrF1287. 
Tongoona L. et al. 2002: Couple counseling in the context of antenatal care: a strategy for reducing STD/HIV risk? Barcelona Conference Abstract: TuPeD 4913

UNAIDS June 1999: Knowledge is power: Voluntary HIV counseling and testing in Uganda. UNAIDS Case Study.

UNAIDS/01.64 October 2001: Working with men for HIV prevention and care. ISBN: 92-9173-123-4 Geneva, Switzerland.

UNICEF. 2002. Draft Report of PMTCT Scaling-Up Meeting. Report of a Meeting Held in Mombassa, Kenya, September 2002.

Vijaykumari JJ 2002: Issues in MTCT program Namakkal, South India. Barcelona conference abstract WePeF 6735.

Veloso VG 2002 HIV Rapid testing during the peripartum period followed by perinatal interventions in Brazil. Barcelona conference abstract ThPeB 7248

Vwalika, C. et al, 2002: Improving VCT uptake in a Zambia District Health Facility. Barcelona Conference Abstract: TuPeD4983

WHO 2000: New Data on the Prevention of Mother-to-Child Transmission of HIV and their Policy Implications - Conclusions and recommendations - WHO/RHR/01.28

WHO Technical Consultation on Behalf of the UNFPA/UNICEF/WHO/UNAIDS InterAgency Task Team on Mother-to-Child Transmission of HIV Geneva, 11-13 October 2000

WHO. 2002. Scaling up antiretroviral therapy in resource-limited settings: guidelines for a public health approach : executive summary. 